\title{
Guidelines for the investigation of chronic diarrhoea, 2nd edition
}

\author{
P D Thomas, A Forbes, J Green, P Howdle, R Long, R Playford, M Sheridan, R Stevens, \\ R Valori, J Walters, G M Addison, P Hill, G Brydon
}

Gut 2003;52(Suppl V):v1-v15

\begin{abstract}
1.0 PREFACE
1.1 Purpose of guidelines

These guidelines were compiled at the request of the Chairman of the British Society of Gastroenterology's clinical services committee. The guidelines are directed at consultant gastroenterologists, specialist registrars in training, and general practitioners, and refer specifically to adult not paediatric gastroenterology. Their purpose is to provide guidance on the best available methods of investigating symptoms of chronic diarrhoea. Given this broad symptom based focus, the guidelines cover a wide range of gastroenterological conditions and are not intended as a comprehensive review of all aspects of the clinical conditions mentioned herein, but rather an attempt to rationalise the approach to investigation in the context of this common clinical scenario.
\end{abstract}

\subsection{Development of guidelines}

The guidelines were prepared following a comprehensive literature search by Dr PD Thomas. This involved a review of electronic databases (Medline and PubMed) using keywords such as "diarrhea", "chronic", "diagnostic evaluation", "investigation", "malabsorption", and terms related to the specific conditions mentioned in the text (for example, coeliac disease and small bowel bacterial overgrowth). Papers relating to diarrhoea in the context of immunodeficiency syndromes were specifically excluded from this review as this subject was felt to require a different investigative approach. A total of 530 key papers and relevant abstracts in English in peer reviewed journals were identified and read, and relevant work has been cited and referenced. An initial draft document was produced and subsequently reviewed and modified by a multidisciplinary group comprising clinical gastroenterologists, radiologists, and biochemists.

\subsection{Grading of recommendations}

The strength of each recommendation is dependant on the category of evidence supporting it and is graded as follows:

A-Requires evidence from at least one randomised controlled trial or a meta-analysis of randomised controlled trials.

$\mathrm{B}$-Requires evidence from prospective, retrospective, or cross sectional clinical studies without randomisation.

C-Evidence based on expert reports or opinion in the absence of directly applicable studies of good quality.

Specific randomised controlled studies addressing the investigation of "chronic diarrhoea" are absent and so these guidelines are based largely on retrospective or small prospective studies, in particular conditions that may give rise to such symptoms, and on expert opinion rather than strict evidence based reasoning (categories B and C).

\subsection{Scheduled review of guidelines}

These guidelines will be subject to future revisions, the first of which is anticipated in August 2005.

\subsection{Possible audit goals}

The aim of these guidelines was to establish an optimal investigative scheme for patients presenting with chronic diarrhoea that would maximise positive diagnosis while minimising the number and invasiveness of investigations. These two potentially opposing directives are influenced by the potential seriousness of the diagnostic outcome. Thus a low threshold for the use of colonoscopy is acceptable in the context of the frequency and clinical significance of colonic neoplasia in older subjects. However, there is less need for extensive investigation where the probability of benign disease is high (for example, in young patients with functional symptoms). Suggested goals for future audit include:

(1) More than $90 \%$ of patients with chronic diarrhoea over 45 years old should undergo appropriate lower gastrointestinal investigation (colonoscopy or flexible sigmoidoscopy with barium enema).

(2) Achieving adequate caecal intubation rates at colonoscopy $(>90 \%)$ with terminal ileal intubation in $>70 \%$ cases if deemed clinically necessary.

(3) Reduction of missed diagnoses of colorectal cancer to $<1 \%$.

(4) Missed diagnoses of inflammatory bowel disease should be $<10 \%$.

(5) Minimising inappropriate first line investigations (for example, barium enema) in patients less than 45 years of age.

(6) Early detection of factitious diarrhoea with minimal invasive investigation.

(7) Initial investigations, including coeliac serology, should be completed in primary care prior to specialist referral.

(8) All units should have access to at least one non-invasive pancreatic function test.

\subsection{INTRODUCTION}

\subsection{Definition}

Diarrhoea may be defined in terms of stool frequency, consistency, volume, or weight. Patients' conceptions of diarrhoea often focus around stool consistency. ${ }^{1}$ Indeed, faecal consistency is determined by the water holding capacity of the stool

Abbreviations: IBS, irritable bowel syndrome; EMA, endomysium antibodies; †TG, tissue transglutaminase: SBBFT, small bowel barium follow through; Tc-HMPAO, technetium hexa-methyl-propyleneamine oxime; $C T$, computerised tomography; ERCP, endoscopic retrograde cholangiopancreatography; $M R C P$, magnetic resonance cholangiopancreatography; NBTP-PABA, N-benzoyl-L-tyrosylp-aminobenzoic acid; cfu, colony forming units; SBBO, small bowel bacterial overgrowth; BAM, bile acid malabsorption; ${ }^{75} \mathrm{Se}-\mathrm{HCAT},{ }^{75} \mathrm{Se}$ homotaurocholate; OCTT, orocaecal transit time; VIP, vasoactive intestinal peptide. 
(that is, the amount of non-bound "free" water) and this perhaps best defines the concept of diarrhoea. ${ }^{1}$ However, quantification of this in clinical practice may prove difficult and so other criteria, such as the passage of more than three stools per day or stool weight, provide alternative means of definition. A stool weight of $200 \mathrm{~g} /$ day is often regarded as the upper limit of normal ${ }^{2}$ but this can be misleading as stool weights vary greatly and "normal" stool volumes can exceed this value, particularly when non-Western diets are encountered. Conversely, distal colonic pathology may not increase stool weight above $200 \mathrm{~g}$ /day. A pragmatic definition incorporates these elements: diarrhoea is the abnormal passage of loose or liquid stools more than three times daily and/or a volume of stool greater than $200 \mathrm{~g} /$ day.

Further potential for confusion arises from the discrepancy between the medical and "lay" concepts of diarrhoea and these need to be clarified at the initial appraisal. Faecal incontinence in particular is commonly misinterpreted as diarrhoea $^{3}$ while symptoms relating to functional bowel disease can be difficult to distinguish from organic pathology on the basis of history alone.

There is no consensus on the duration of symptoms that define chronic as opposed to acute diarrhoea. However, most groups would accept that symptoms persisting for longer than four weeks suggest a non-infectious aetiology and merit further investigation. ${ }^{4}$

\subsection{Prevalence}

Chronic diarrhoea is one of the most common reasons for referral to a gastroenterology clinic. Prevalence rates in Western populations are difficult to estimate, partly through population differences, but also through difficulties in definition. In two population surveys, Talley et al reported a prevalence of "chronic diarrhoea" of between $7 \%$ and $14 \%$ in an elderly population, a proportion of which was likely to include patients with motility disorders (that is, 'functional bowel disease). Using a definition based on excessive stool frequency without the presence of abdominal pain, estimates of the prevalence of chronic diarrhoea in a Western population are of the order of $4-5 \% .^{56}$

\subsection{Difficulties in establishing guidelines for the investigation of chronic diarrhoea}

Reported change in stool frequency or form is characteristic of irritable bowel syndrome (IBS) and indeed forms part of the definition of the condition. ${ }^{78}$ Although stool weight does not usually increase in IBS, as symptom reporting forms the basis for the diagnosis and stool weight is rarely performed early in the course of investigation, considerable overlap between functional bowel disease and true "diarrhoea" occurs. As IBS may affect $9-12 \%{ }^{9}$ of the population, there is clearly the potential for inappropriate investigation of patients reporting diarrhoeal symptoms. Conversely, new onset of diarrhoea may reflect serious organic disease such as colonic neoplasia. It is this wide diagnostic potential given similar reported symptoms that makes the introduction of specific guidelines difficult.

The broad range of conditions which lead to diarrhoea also make it difficult to be too proscriptive with regards to the investigative pathways that should be adopted. Diarrhoea may result from: (a) colonic neoplasia/inflammation; (b) small bowel inflammation; (c) small bowel malabsorption; (d) maldigestion due to pancreatic insufficiency; or (e) motility disorders, and it can be difficult to separate these on clinical grounds. The decision on whether to focus investigations on any one of these areas remains largely a matter of clinical judgement although, as will be discussed, the prevalence and potential seriousness of certain conditions (for example, colonic neoplasia) necessitates their exclusion early in the investigative scheme.
A further problem in the development of these guidelines has been the large number of investigative methods reported, particularly with regard to malabsorption. This reflects the failure of any single test to become established as the standard and, indeed, many of the available methods have not found a wide acceptance because of inadequate sensitivity, specificity, or ease of use. Moreover, there is considerable variation in protocols and analytical methods between laboratories that leads to poor reproducibility of results. ${ }^{10}$ It is also unclear what place some of these tests ( some of which were devised prior to the advent of endoscopy) hold in the current investigative scheme that incorporates access to small bowel and colonic histology.

\section{Summary}

- Chronic diarrhoea may be defined as the abnormal passage of three or more loose or liquid stools per day for more than four weeks and/or a daily stool weight greater than $200 \mathrm{~g} /$ day.

- A clinical definition of chronic diarrhoea based on symptom reporting alone will lead to an overlap with functional bowel disorders such as irritable bowel syndrome.

\subsection{INITIAL ASSESSMENT}

The initial assessment of patients with chronic diarrhoea can be mostly carried out in the primary care setting. Routine blood, stool (if an infectious aetiology is suspected), and serological tests (for coeliac disease) should be performed. Open access flexible sigmoidoscopy, if available, may also be utilised. Although stool and urine testing for laxative abuse may be requested at this stage it may be difficult to exclude this as a cause of diarrhoea in this setting. An algorithm for the investigation of chronic diarrhoea is shown in fig 1 .

\subsection{History and examination}

A detailed history is essential in the assessment of patients with chronic diarrhoea. This should attempt (a) to establish the likelihood that the symptoms are organic (as opposed to functional), (b) to distinguish malabsorptive from colonic/ inflammatory forms of diarrhoea, and (c) to assess for specific causes of diarrhoea.

Symptoms suggestive of an organic disease include a history of diarrhoea of less than three months' duration, predominantly nocturnal or continuous (as opposed to intermittent) diarrhoea, and significant weight loss. The absence of these, in conjunction with positive symptoms such as those defined in the Manning or Rome criteria ${ }^{78}$ and a normal physical examination, are suggestive of a functional bowel disturbance, but only with a specificity of approximately $52-74 \% .{ }^{11-13}$ Unfortunately, these criteria do not reliably exclude inflammatory bowel disease. ${ }^{14-16}$

Malabsorption is often accompanied by steatorrhoea and the passage of bulky malodorous pale stools. However, milder forms of malabsorption may not result in any reported stool abnormality. Colonic, inflammatory, or secretory forms of diarrhoea typically present with liquid loose stools with blood or mucous discharge. Inspection of the stool may be helpful in distinguishing these two.

Specific risk factors, which increase the likelihood of organic diarrhoea or point to potential lines of investigation, should be sought (see table 1). These include:

(1) Family history. Particularly of neoplastic, inflammatory bowel, or coeliac disease.

(2) Previous surgery. Extensive resections of the ileum and right colon lead to diarrhoea due to lack of absorptive surface and hence fat and carbohydrate malabsorption, decreased transit time, or malabsorption of bile acids and a smaller bile acid 


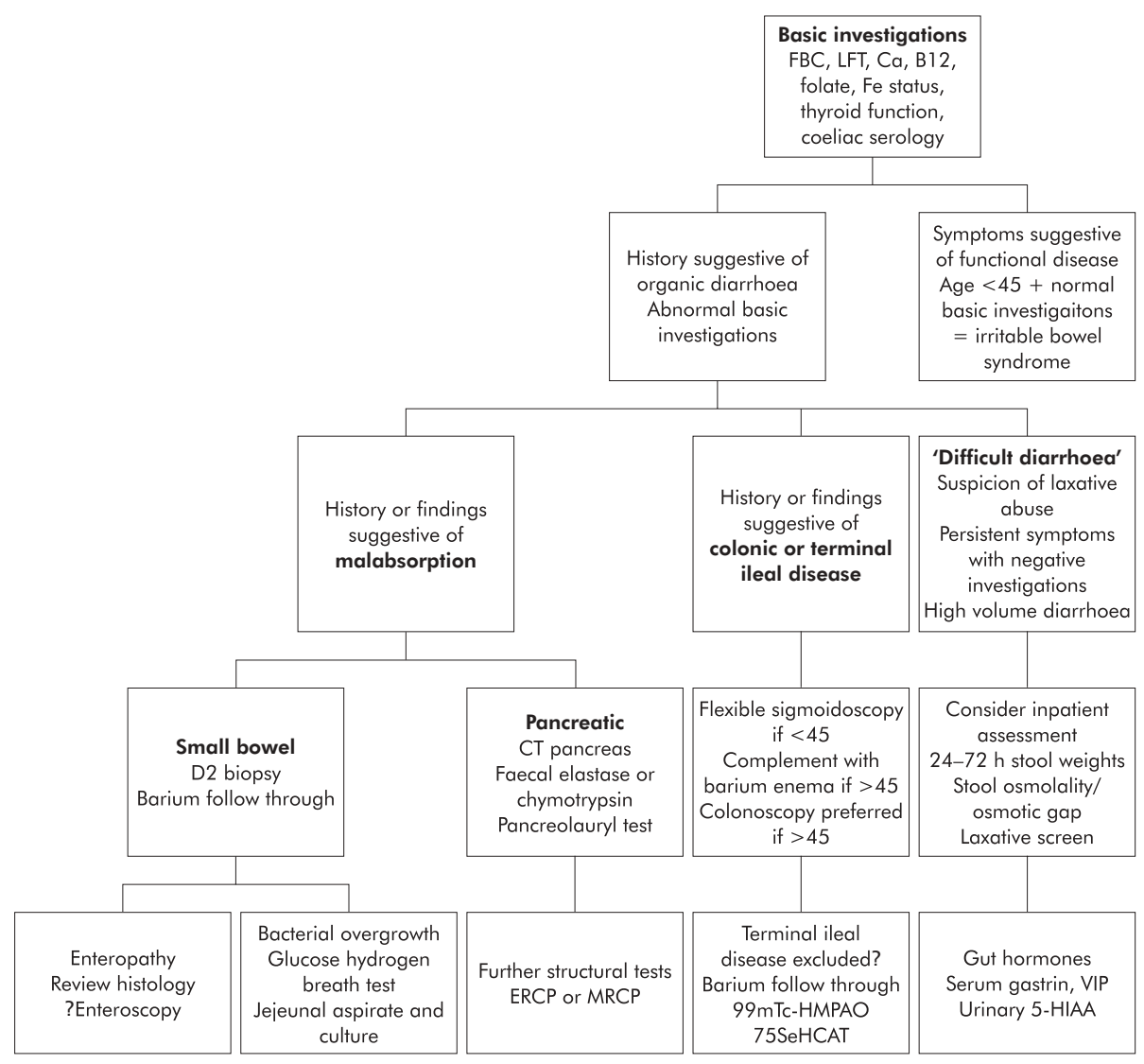

Figure 1 An algorithm for the investigation of chronic diarrhoea (see text for details). FBC, full blood count; LFT, liver function tests; CT, computerised tomography; ERCP, endoscopic retrograde cholangiopancreatography; $M R C P$, magnetic resonance cholangio-

pancreatography; Tc-HMPAO, technetium hexa-methylpropyleneamine oxime; ${ }^{75} \mathrm{Se}-\mathrm{HCAT}$ ${ }_{75} \mathrm{Se}$ homotaurocholate; $5 \mathrm{HIAA}$ 5-hydroxyindoleacetic acid.

Table 1 Causes of chronic diarrhoea

Colonic

Colonic neoplasia

Ulcerative and Crohn's colitis

Microscopic colitis

Small bowel

Coeliac disease

Crohn's disease

Other small bowel enteropathies (for example, Whipple's disease,

tropical sprue, amyloid, intestinal lymphangiectasia)

Bile acid malabsorption

Disaccharidase deficiency

Small bowel bacterial overgrowth

Mesenteric ischaemia

Radiation enteritis

Lymphoma

Giardiasis (and other chronic infection)

Pancreatic

Chronic pancreatitis

Pancreatic carcinoma

Cystic fibrosis

Endocrine

Hyperthyroidism

Diabetes

Hypoparathyroidism

Addison's disease

Hormone secreting tumours (VIPoma, gastrinoma, carcinoid)

Other

Factitious diarrhoea

"Surgical" causes (e.g. small bowel resections, internal fistulae)

Drugs

Alcohol

Autonomic neuropathy

pool. ${ }^{17}$ Bacterial overgrowth can often be a problem in this situation, particularly in bypass operations such as in gastric surgery and jejunoileal bypass procedures for morbid obesity. Shorter resections of the terminal ileum can lead to bile acid diarrhoea that typically occurs after meals and usually responds to fasting and cholestyramine (see section 7.2). Chronic diarrhoea may also occur in up to $10 \%$ patients after cholecystectomy through mechanisms that include increased gut transit, bile acid malabsorption, and increased enterohepatic cycling of bile acids. ${ }^{18}{ }^{19}$

(3) Previous pancreatic disease

(4) Systemic disease. Thyrotoxicosis and parathyroid disease, diabetes mellitus, adrenal disease, or systemic sclerosis may predispose to diarrhoea through various mechanisms, including endocrine effects, autonomic dysfunction, small bowel bacterial overgrowth, or the use of concomitant drug therapy. ${ }^{20}$

(5) Alcohol. Diarrhoea is common in alcohol abuse. Mechanisms include rapid gut transit, decreased activity of intestinal disaccharidases, and decreased pancreatic function ${ }^{21}$

(6) Drugs. Up to $4 \%$ of cases of chronic diarrhoea may be due to medications (particularly magnesium containing products, antihypertensive and non-steroidal anti-inflammatory drugs, theophyllines, antibiotics, antiarrhythmics, and antineoplastic agents) and food additives such as sorbitol and fructose, and these should be carefully sought. ${ }^{22}$

(7) Recent overseas travel or other potential sources of infectious gastrointestinal pathogens.

(8) Recent antibiotic therapy and Clostridium difficile infection. Many different tests are now available for the detection of $C$ difficile but most clinical laboratories use a commercial enzyme immunoassay for $C$ difficile toxin.

9. Lactase deficiency (see section 7.3).

\subsection{Initial investigations}

\subsubsection{Blood tests}

Abnormal initial screening investigations such as a high erythrocyte sedimentation rate, anaemia, or low albumin have a high specificity for the presence of organic disease. ${ }^{1323}$ The 
presence of iron deficiency is a sensitive indicator of small bowel enteropathy, particularly coeliac disease, ${ }^{24}$ but is obviously not a specific test. Guidelines regarding the approach to a patient with iron deficient anaemia have previously been published. ${ }^{25} \mathrm{~A}$ basic screen for evidence of malabsorption should include full blood count, urea and electrolytes, liver function tests, vitamin B12, folate, calcium, ferritin, erythrocyte sedimentation rate, and $\mathrm{C}$ reactive protein. Thyroid function tests should also be performed at this stage.

\subsubsection{Serological tests for coeliac disease}

Coeliac disease is the most common small bowel enteropathy in the Western world, frequently presenting with diarrhoea due to steatorrhoea and malabsorption. Serological screening studies using IgA antiendomysium antibodies (EMA) or reticulin antibodies have shown a prevalence of between 1:200 and 1:559 in European and North American populations. ${ }^{26-30}$ The prevalence is considerably higher when there is an associated autoimmune disease present (for example, insulin dependent diabetes, thyroid disease, or primary biliary cirrhosis) or in patients with Down's syndrome. ${ }^{31}$ Many individuals are however asymptomatic-in one study only $46 \%$ had disturbance in bowel function with loose stools or steatorrhoea, suggesting that the prevalence in a symptomatic cohort may be higher. ${ }^{27}$ As such, there is a strong case for routine serological testing for coeliac disease for all patients presenting with "diarrhoea". The recent identification of tissue transglutaminase (tTG) as the autoantigen of $\mathrm{EMA}^{32}$ has led to the development of commercial ELISA kits for the detection of anti-tTG antibodies. ${ }^{33}$ Most studies to date show no advantage in sensitivity compared with EMA for the detection of coeliac disease and inferior specificity. However, the development of methods based on human tTG is likely to improve the diagnostic accuracy. If confirmed, given the analytical advantages over EMA, this is likely to become the preferred serological test for coeliac disease in the near future. ${ }^{34-38}$

Reliance on serological testing for coeliac disease should be tempered with the knowledge that the condition is associated with selective IgA deficiency, which will give rise to false negative serum IgA antibody tests. Selective IgA deficiency occurs in 1:500 $(0.2 \%)-1: 700(0.14 \%)$ of the general population but in $2.6 \%$ of patients with coeliac disease. ${ }^{39-41}$ A recent study ${ }^{42}$ has shown that both IgG antiendomysium and IgG anti-tTG antibodies may be suitable alternative serological means of diagnosing coeliac disease but are not suitable for monitoring the response to dietary modification. Antiendomysium IgA antibodies, in contrast, disappear following adequate treatment with a gluten free diet. ${ }^{42}$ As such, one should consider requesting IgG, in addition to IgA serology, or checking total IgA levels when there is a high degree of suspicion regarding the diagnosis.

\subsubsection{Stool tests}

Given the difficulty of assessing diarrhoea based on history alone, inspection of the stool may be helpful. This can readily be performed in the course of a rigid sigmoidoscopy without bowel preparation. Ideally, stool weights over a $24-48$ hour period should be recorded and may limit unnecessary investigation if values $<200 \mathrm{~g} /$ day are obtained. However, in practical terms this is difficult to achieve in an outpatient setting and as such may be reserved for difficult cases, particularly where factitious diarrhoea is suspected, and collections will then be performed under inpatient supervision.

Stool tests may be divided into specific and non-specific tests. There are few specific stool tests available but these are of value. These include tests for pancreatic enzymes such as faecal elastase, which is discussed in section 6.4.2. Nonspecific stool tests are of questionable use. Measurement of stool (faecal fluid) osmolality and calculation of the osmotic gap have long been reputed to be of value in differentiating osmotic, secretory, and factitious diarrhoea but their reliability has not been subjected to any rigorous testing. Certainly, this approach is seldom of practical use in most cases of chronic diarrhoea and is non-specific. Nevertheless, in difficult cases, particularly where factitious diarrhoea is suspected, these measurements may provide an aid to diagnosis.

Low stool osmolality ( $<290 \mathrm{mosmol} / \mathrm{kg}$ ) suggests contamination of stool with dilute urine, water, or excess ingestion of hypotonic fluid. Measurement of stool creatinine can be used to assess the former. Faecal fluid osmolality is similar to that of serum even in patients taking laxatives or those with osmotic or secretory diarrhoea. ${ }^{43}{ }^{44}$ The faecal osmotic gap is calculated from the following formula: (290-2× (sodium + potassium concentration)). Faecal sodium and potassium concentrations are measured in stool water after homogenisation and centrifugation. The osmotic gap of faecal fluid can be used to estimate the contribution of electrolytes and non-electrolytes to retention of water in the intestinal lumen. In secretory diarrhoea, unabsorbed electrolytes retain water in the lumen while in osmotic diarrhoea non- electrolytes cause water retention. Thus the osmotic gap should be large $(>125$ mosmol $/ \mathrm{kg}$ ) in osmotic diarrhoea and small $(<50 \mathrm{mosmol} / \mathrm{kg})$ in secretory diarrhoea. ${ }^{44}$ Further differentiation of osmotic and secretory diarrhoea may be provided by a trial of a 48 hour fast (usually as an inpatient). Continuation of diarrhoea despite this implies a secretory or factitious cause while cessation of diarrhoea during the fast is highly suggestive of osmotic diarrhoea.

Chronic diarrhoea due to infectious agents is rare in immunocompetent Western populations but stool cultures should be considered, particularly where there is a history of travel to high risk areas. Protozoan infections, such as giardiasis and amoebiasis, are most likely to result in chronic infections. Examination of three fresh stools for ova, cysts, and parasites remains the mainstay of diagnosis and has a sensitivity of approximately $60-90 \%$ for detection of these organisms. If there is doubt about persisting Giardia infection, then the use of a stool ELISA (92\% sensitivity and 98\% specificity) has largely replaced the need for intestinal biopsies and wet preparations ${ }^{45-47}$ Serological testing is not effective in cases of suspected giardiasis but can be useful in amoebiasis where positive serology by an indirect haemagglutination test or ELISA can differentiate invasive disease from the asymptomatic carrier state. ${ }^{48}$

Stool analysis for fat is discussed in section 5.1.1. The role of other stool investigations remains, at present, unclear. Faecal occult blood testing has been used widely in screening for neoplasia but its role in the evaluation of diarrhoea has not been defined. Stool markers of gastrointestinal inflammation such as lactoferrin ${ }^{49}$ and, more recently, calprotectin, are of considerable research interest but, as yet, these have not been introduced into clinical practice..$^{50} 51$

\subsection{Factitious diarrhoea}

Factitious diarrhoea caused by laxative abuse or the spurious adding of water or urine to stool specimens is a common cause of reported chronic diarrhoeal symptoms in Western populations. The likelihood of this diagnosis increases as more numerous and repeated investigations reveal negative results. Thus although only $4 \%$ of patients visiting district gastroenterology clinics had factitious diarrhoea, this value increased to $20 \%$ of those evaluated at tertiary referral centres, making it the most common cause of diarrhoea of previously undetermined origin..$^{52}$ Similarly, a survey of patients who had undergone extensive evaluation revealed $33 \%$ who were found to be taking laxatives or diuretics; $22 \%$ had undiagnosed colitis (ulcerative or microscopic colitis), $7 \%$ had faecal incontinence, and $7 \%$ had other organic disorders. ${ }^{23}$

A high index of suspicion is necessary to prevent extensive and needless investigation. Patients who abuse laxatives often 
have a psychiatric history, particularly that of an eating disorder, and have abnormal views on body shape or form, or have a connection with the health professions. ${ }^{534}$ Although individuals who abuse laxatives may have major metabolic derangements and clinical manifestations (clubbing, hyperpigmentation of the skin, steatorrhoea, colonic inflammation, kidney stones, and osteomalacia), these are unusual and there are often few physical cues.

Dilutional, secretory, or osmotic diarrhoea may occur in factitious diarrhoea. Dilutional diarrhoea should be suspected in individuals with an abnormal faecal fluid osmolality (section 3.2.3). If faecal osmolality is less than $290 \mathrm{mosmol} / \mathrm{kg}$ (the osmolality of plasma) then water or a hypotonic solution has been added to the stool. ${ }^{55}{ }^{56}$ Osmotic diarrhoea may occur as a result of ingestion of magnesium salts. A soluble faecal $\mathrm{Mg}$ concentration greater than $45 \mathrm{mmol} / \mathrm{l}$ strongly suggests $\mathrm{Mg}$ induced diarrhoea.

Repeated analysis of stool and urine is wise, as patients may ingest laxatives intermittently. Screening tests for laxative abuse should be by spectrophotometric or chromatographic analysis. ${ }^{57-59}$ Alkalinisation assays, although simple to use, (phenolphthalein, some anthraquinones and rhubarb turn the stool red, bisacodyl turns it purple-blue) are not of sufficient sensitivity and should be abandoned. A screen for "laxative abuse" should include the detection of anthraquinones, bisacodyl, and phenolphthalein in urine, and magnesium and phosphate in stool, and should be carried out in a specialist laboratory. Laboratories in the UK performing these tests should participate in the UK External Quality Assessment scheme for the detection of laxatives.

Such patients may be difficult to diagnose in an outpatient setting and hospital admission may be required to document stool volumes while concurrent laxative screens are performed. In this context the issue of "locker searches" of a patient's belongings for laxatives remains a contentious issue with varying views on the ethics of this approach. ${ }^{60}$

\section{Summary and recommendations}

- Screening blood tests should include full blood count, erythrocyte sedimentation rate, $C$ reactive protein, urea and electrolytes, liver function tests, calcium, vitamin B 12 folate, iron studies, and thyroid function. These have a high specificity but low sensitivity for the presence of organic disease (B).

- Although infectious diarrhoea is uncommon in immunocompetent patients from the developed world with chronic symptoms, stool cultures and stool microscopy should be performed (C)

- Coeliac disease is the most common small bowel enteropathy in Western populations. Patients with diarrhoea should be screened for this using serological tests (currently antiendomysium antibodies), which have a high sensitivity and specificity for the disease (A).

- Factitious diarrhoea becomes increasingly common in specialist referral practice, and screening for laxative abuse should be performed early in the course of investigation (B).

\subsection{SMALL AND LARGE BOWEL MUCOSAL DISEASE 4.1 Endoscopic and histological assessment}

\subsubsection{Flexible sigmoidoscopy}

In most patients with chronic diarrhoea, some form of endoscopic investigation will be necessary. However, in cases where malabsorption is suspected, investigations should be directed along the lines suggested in the sections devoted to pancreatic or small bowel malabsorption. In young patients (less than 45 years) reporting "diarrhoea" but who have other typical symptoms of a functional bowel disorder and negative initial investigations, a diagnosis of IBS may be made in the primary care setting without recourse to further investigations. ${ }^{9}$ However, patients under 45 years with atypical and/or severe symptoms and documented diarrhoea (as previously defined) should have further evaluation.

Unprepared rigid sigmoidoscopy has long been used in the outpatient setting to quickly assess the rectum and stool. This remains an appropriate examination in those younger patients who on clinical grounds are believed to have a functional bowel disorder. However, in patients with chronic diarrhoea, flexible endoscopy is the preferred examination, allowing assessment of the sigmoid and descending colon and sampling of the colonic mucosa for histological examination. Several authors have shown that, in this age group, most pathology occurs in the distal colon and is thus accessible with a flexible sigmoidoscope. ${ }^{46162}$ In a study that examined the prevalence and anatomical distribution of colonic pathology in patients presenting with non-human immunodeficiency virus related chronic diarrhoea, it was demonstrated that $15 \%$ of patients had colonic pathology ${ }^{62}: 99.7 \%$ of these diagnoses could have been made from biopsies of the distal colon using a flexible sigmoidoscope, the primary diagnoses being microscopic colitis, Crohn's disease, melanosis coli, and ulcerative colitis.

\subsubsection{Colonoscopy}

Diarrhoea may be caused by colorectal neoplasia. Studies of screening colonoscopy in asymptomatic individuals have shown a prevalence of colonic adenomas of between $14.4 \%$ and $37.5 \%(7.9 \%$ with adenomas $>10 \mathrm{~mm}) .{ }^{63}{ }^{64}$ This prevalence is strongly influenced by age, male sex, and a history of a first degree relative with colorectal cancer. ${ }^{6365}{ }^{66} \mathrm{Few}$ studies have addressed the frequency of neoplasia in symptomatic patients, and none has specifically addressed the prevalence of adenomas in patients undergoing colonoscopy for diarrhoea. However, Neugut and colleagues ${ }^{67}$ showed a prevalence of colonic neoplasms of $27 \%$ in those patients undergoing colonoscopy for a change in bowel habit, a value which approached the yield of $33.6 \%$ in patients with a history of rectal bleeding. A large proportion (approximately $50 \%$ ) had neoplasia proximal to the splenic flexure, indicating the need for full colonoscopy rather than flexible sigmoidoscopy in these patients. ${ }^{6467}$

In addition to neoplasia, colonoscopy also has a diagnostic yield for other conditions ranging from $7 \%$ to $31 \%$, with inflammatory bowel disease and microscopic colitis being most commonly found. ${ }^{61}{ }^{68-70}$ Routine ileoscopy further adds to the value of colonoscopy. While this led to a positive diagnosis in only $2.7 \%$ of asymptomatic patients undergoing surveillance colonoscopy, this increased to $18 \%$ in non-HIV patients who complained of diarrhoea. ${ }^{71}$ In patients in whom a diagnosis of inflammatory bowel disease is suspected, the value of ileoscopy and biopsy is further enhanced: $36 \%$ of patients with a normal colonoscopy and diarrhoea had terminal ileal disease. ${ }^{72}$ These results are subject to considerable referral bias but when taken together they suggest that in chronic diarrhoea, colonoscopy and ileoscopy with biopsy may lead to a diagnosis in approximately $15-20 \%$ of cases, a value that may approach $40 \%$ in those patients with suspected inflammatory bowel disease.

Colonoscopy is also the preferred modality to exclude or confirm microscopic colitis. Lymphocytic and collagenous colitis (collectively called microscopic colitis) are conditions with a similar natural history and often (in 25-30\%) overlapping features. ${ }^{73}$ These conditions have increasingly been identified as a cause of diarrhoea in patients with macroscopically normal mucosa. Although the diagnosis has often relied on biopsies obtained at flexible sigmoidoscopy, recent studies have pointed to the high false negative yield from rectosigmoid histology (34-43\%). These authors recommend samples from the ascending and transverse colon to maximise the likelihood of correct diagnosis. ${ }^{756}$ 
Colonoscopy is a more sensitive test than barium enema and given this, and the need to obtain histology to exclude colitis, the former investigation is recommended. ${ }^{77} 78$

\subsubsection{Upper gastrointestinal endoscopy}

There is little information on the diagnostic yield of upper gastrointestinal endoscopy in patients whose diarrhoea is suspected to be due to malabsorption. This will clearly vary depending on the cohort of patients being investigated, referral criteria, and degree of suspicion for any given underlying diagnosis. Antiendomysium IgA antibody is currently the preferred firstline test for coeliac disease rather than endoscopic duodenal biopsy in patients with diarrhoea and/or malabsorption. However, distal duodenal biopsies should be performed in those patients in whom small bowel malabsorption is suspected on clinical grounds, even in the absence of positive antiendomysium antibodies to assess for the presence of other small bowel enteropathies.

\subsection{Small bowel imaging and enteroscopy}

Although total colonoscopy and ileoscopy is likely to represent the gold standard for excluding inflammatory disease in the ascending colon and terminal ileum, in some cases endoscopy will be incomplete. Consequently, further imaging of the terminal ileum and proximal colon may be warranted.

The small bowel barium follow through (SBBFT) or barium enteroclysis remains the standard means of assessing small bowel mucosa, although there is some controversy over their value. Some groups report both a low sensitivity and specificity $^{79}$ while others suggest a specificity for excluding small bowel disease of $92 \%{ }^{80}$ These results are in part explained by the low incidence of small bowel disorders and it is likely that a negative result offers reasonably reliable exclusion of macroscopic small bowel disease (see small bowel enteroscopy, below). Debate also continues over the relative merits of enteroclysis and SBBFT. Bernstein and colleagues ${ }^{81}$ found little difference between the two techniques in the diagnosis or exclusion of small bowel disease in Crohn's patients while others have found enteroclysis to be superior. ${ }^{79}$ It is likely that in expert hands SBBFT is of equivalent sensitivity and specificity to enteroclysis.

Small bowel enteroscopy has been evaluated as a complementary investigation to SBBFT, either as a means to distinguish small bowel abnormalities or to assess further the small bowel after a negative radiological investigation. ${ }^{83}$ The diagnostic yield in this series appeared high $31.5 \%$ of enteroscopy procedures giving a positive diagnosis in patients with a normal SBBFT, and $48.2 \%$ of investigations leading to a diagnosis in those with abnormal SBBFT) but failure to exclude adequately patients with small bowel enteropathy (accessible for diagnosis using conventional duodenal biopsies) may have artificially raised this yield. Removal of these cases led to an overall diagnostic rate of approximately $20 \%$, which is in keeping with the $22 \%$ diagnostic yield using this procedure that was achieved by Landi and colleagues ${ }^{84}$ in cases with chronic diarrhoea and/or malabsorption. Although the role of small bowel enteroscopy remains to be defined, it seems unlikely it will be of benefit in most cases of malabsorption believed to be due to small bowel disease.

A key feature of enteroscopy studies is the consistently high false negative rate of prior upper and lower endoscopy, emphasising the need to ensure that adequate visualisation and biopsy of the duodenum and ileum have been achieved. In some cases this may necessitate a repeat endoscopy. Where this is not possible, alternative methods of small bowel visualisation are required, particularly in relation to excluding inflammatory activity within the small bowel.

Segal and colleagues ${ }^{85}$ first described the use of radiolabelled white cells in the investigation of inflammatory bowel disease in 1981. Subsequent use of ${ }^{99 \mathrm{~m}}$ technetium hexamethyl-propyleneamine oxime (Tc-HMPAO) was shown to offer superior imaging, a simpler labelling technique, and equivalent results to ${ }^{11}$ indium scanning, with the additional advantage of a greatly reduced radiation burden. ${ }^{86}{ }^{87}$ This technique has recently been assessed in relation to colonoscopy with biopsy and SBBFT in the diagnosis of inflammatory bowel disease in children, to whom the technique is particularly suited. Tc-HMPAO had equivalent sensitivity and specificity to endoscopy with biopsy while SBBFT showed a sensitivity of only $42 \%$. Tc-HMPAO would therefore appear to be an alternative means to diagnose or exclude small bowel inflammatory disease in the absence of endoscopic ileal access.

\section{Summary and recommendations.}

- In patients less than 45 years with typical symptoms of functional bowel disease, normal examination, and normal screening blood tests, a positive diagnosis can be made and no further investigation is necessary (C).

- Patients less than 45 years with chronic diarrhoea and/or atypical symptoms should undergo flexible sigmoidoscopy in the first instance as the diagnostic yield differs little from the use of colonoscopy in this age group (B).

- In patients over 45 years with chronic diarrhoea, colonoscopy (with ileoscopy) is the preferred investigation. This may yield abnormalities in up to $30 \%$ of cases, has a better sensitivity than barium enema, and allows sampling of the colonic mucosa for histological examination (B).

- Antiendomysium antibody testing is currently the preferred firstline test for coeliac disease but if negative and small bowel malabsorption is suspected, upper gastrointestinal endoscopy with distal duodenal biopsies should be performed to assess for the presence of other small bowel enteropathies (C).

- Small bowel imaging (barium follow through or enteroclysis) should be reserved for cases where small bowel malabsorption is suspected and distal duodenal histology is normal (C).

- ${ }^{99 m}$ Technetium hexa-methyl-propyleneamine oxime (TcHMPAO) labelled white cell scanning is a non-invasive useful technique to examine for intestinal inflammation and has equivalent sensitivity to small bowel follow through in the assessment of terminal ileal Crohn's disease (B).

\subsection{NON-INVASIVE TESTS FOR MALABSORPTION}

Malabsorption may occur as a result of defective luminal digestion due to lack of pancreatobiliary enzymes, or from failure of absorption due to mucosal disease or structural disorders. Although there is generally a combination of fat, carbohydrate, protein, vitamin, and mineral deficiencies, a predominance of one or other of these may exist. Thus pancreatic exocrine insufficiency is the usual cause of severe and dominant steatorrhoea where faecal fat excretion exceeds $13 \mathrm{~g} /$ day $(47 \mathrm{mmol} /$ day $) .{ }^{88}$ This is rare in mucosal or structural disease although milder forms of steatorrhoea commonly occur. In comparison, carbohydrate malabsorption is predominantly associated with mucosal disease or dysfunction.

Approaches to the investigation of malabsorption involve either measurement of an absorbed test substance in blood or urine or detection in faeces of a substance that has not been absorbed. A variation of the latter is the use of breath testing which relies on the breakdown of the malabsorbed test substance by colonic flora.

\subsection{Tests for fat malabsorption}

\subsubsection{Stool fat}

Three day collection of stools for measurement of unabsorbed fat has been the standard test for malabsorption for decades and continues to be used by British gastroenterologists. ${ }^{10}$ However, there are several limitations to the technique including difficulty in collecting complete three day samples, lack of 
quality control of analysis, and lack of standardisation between laboratories. ${ }^{10}$ For these reasons, its increasingly curtailed availability, and the limited diagnostic information provided by a positive result, some authors have suggested that routine use of the test be abandoned. ${ }^{89}$

Alternative methods of assessing fat malabsorption have been developed which rely on single stool analysis of fat content or analysis of radiolabelled byproducts of fat hydrolysis on breath testing. However, these techniques are not widely available in the UK and their role is somewhat in question given their generally limited sensitivity for mild fat malabsorption and lack of diagnostic specificity. In general, more specific investigations such as stool elastase or antiendomysium antibodies are recommended. However, in situations where these tests are negative and malabsorption still suspected, single stool tests for fat may be a useful adjunct if available.

Faecal fat concentration ( $\mathrm{g}$ faecal fat/100 g wet stool weight) is reported to correlate well with total fat excretion (correlation coefficients of 0.86-0.97). ${ }^{90-95}$ Other methods for estimation of faecal fat in stool are semiquantitative and give a moderate correlation with quantitative methods. The stool steatocrit involves separating a faecal homogenate by centrifugation into a lipid, water, and solid phase. Faecal acidification much improves this method with a correlation with three day faecal fat of $0.761 .{ }^{96}$ Sudan III staining of stools has also been used as a qualitative test for fat malabsorption and more recently has been adapted to give a quantitative result. ${ }^{97}$ Both stool steatocrit and Sudan III stool staining may be considered to be useful simple semiquantitative tests in the investigation of fat malabsorption although it is questionable whether they are superior to a visual assessment of stool for fat. ${ }^{98}$

\subsubsection{Breath tests}

Breath tests for fat malabsorption offer an attractive alternative to stool tests. ${ }^{14} \mathrm{C}$-triolein absorption has been used as an alternative to faecal fat. The test assesses both lipolysis and absorption. Sensitivities of $85-100 \%$ have been reported with specificity $>90 \%$ using a fat load of about $20 \mathrm{~g},{ }^{99-101}$ although lower sensitivity has been reported when faecal fat is only 7-14 g/day (25-50 mmol/day) ${ }^{.02}$ However, larger fat loads lead to delays in ${ }^{14} \mathrm{CO}_{2}$ excretion and the test procedures are not well standardised. The test is inappropriate in patients with diabetes, liver disease, or obesity.

Fat absorption tests based on stable (that is, nonradioactive) isotopes have also been developed using a variety of ${ }^{13} \mathrm{C}$-substrates. ${ }^{103-106}{ }^{13} \mathrm{C}$-Hiolein is a long chain triglyceride obtained from algae. The procedure involves oral administration of ${ }^{13} \mathrm{C}$-Hiolein $(2 \mathrm{mg} / \mathrm{kg}$ ) given with a rice snack, with subsequent breath ${ }^{13} \mathrm{CO}_{2}$ measured by mass spectrometry. Sensitivity and specificity values are comparable with those for ${ }^{14} \mathrm{C}$-triolein. ${ }^{103} \mathrm{~A}{ }^{13} \mathrm{C}$ mixed chain triglyceride has also been used in children ${ }^{104}$ and adults. ${ }^{105}$ This substrate has a medium chain fatty acid in the 2 position and is designed to assess intraluminal pancreatic lipase activity. Ventrucci and colleagues ${ }^{106}$ have used ${ }^{13} \mathrm{C}$-cholesteryl octanoate to assess pancreatic exocrine insufficiency but were unable to detect mild/moderate dysfunction satisfactorily.

\subsection{Tests for protein loss}

Proteins are digested into polypeptides and amino acids in the gut lumen by pancreatic enzymes before active absorption. Malabsorption of these breakdown products rarely occurs in the absence of fat or carbohydrate malabsorption. This, and the fact that measurement of protein absorption is difficult and unreliable, means that assessments of protein malabsorption are rarely performed in clinical settings. Two methods have been described, namely faecal clearance of $\alpha_{1}$-antitrypsin ${ }^{107}$ or radiolabelled albumin, ${ }^{108}$ the former being available in a few service laboratories.

\subsection{Non-invasive tests for small bowel enteropathy}

Prior to the advent of endoscopic biopsy, assessment of small bowel mucosal function was primarily achieved by quantifying absorption of the inert sugar D-xylose. D-Xylose absorption is largely by passive diffusion ${ }^{109}$ and thus its absorption reflects breakdown of the intestinal barrier and increased intestinal permeability, as seen in small bowel enteropathy, rather than an active absorptive process. Although widely offered in hospital laboratories $(72 \%$ of British hospitals offered this service in a recent survey) and despite literature supporting a good correlation with histological abnormalities, ${ }^{110}{ }^{111}$ it is sensitive rather than specific, and the analytical performance of the test is poor in routine practice. As such it is becoming largely superseded by access to small bowel histology obtained at endoscopy and/or serological tests for coeliac disease. ${ }^{10}$

The non-invasive measurement of intestinal permeability has been an established research tool for almost 20 years but is not used widely in clinical practice. The procedure involves oral administration of two test probe substances. Typically, these include substances with a differing molecular weight and hence different rates and routes of absorption and urinary excretion. Examples include multiple ethylene glycol polymers of different molecular weights, a mixture of oligosaccharide (for example, lactulose) and monosaccharide (for example, L-rhamnose or mannitol), or the use of a non-degraded radiolabelled chelate (for example, ${ }^{51} \mathrm{Cr}$-EDTA). Differential urinary excretion is then quantified for the test substances and a specific index of intestinal permeability obtained. The procedure is similar to urinary D- xylose testing but the use of two probes negates the effect of pre or post mucosal factors that influence the results. An abnormal result is also non-specific and non-diagnostic, other than establishing the existence of a mucosal abnormality. However, intestinal permeability measurements have been widely used in the research setting in Crohn's disease, coeliac disease, and non-steroidal anti-inflammatory drug enteropathy, and have been advocated as a screening tool and a non-invasive test of clinical response in coeliac disease and other small bowel enteropathies. ${ }^{112}$

\section{Summary and recommendations}

- Quantification of three day faecal fat is poorly reproducible, unpleasant, and non-diagnostic, and its use should be discouraged (C).

- Single stool analyses such as faecal fat concentration and semiquantitative methods such as acid steatocrit correlate moderately well with three day faecal fat quantification and offer an alternative method of assessing fat malabsorption but are not readily available in most centres. Newer specific tests of pancreatic dysfunction, such as stool elastase, are preferred (B)

- Breath tests for fat malabsorption include ${ }^{14} \mathrm{C}$-triolein or a ${ }^{13} \mathrm{C}$ labelled mixed triglyceride as substrates. These have a low sensitivity for mild or moderate fat malabsorption but where available may serve as an alternative to faecal fat collection (B).

- Non-invasive investigations for small bowel enteropathy such as urine or serum D-xylose testing, although of high sensitivity in clinical studies, often have a poor performance in routine practice and have largely been superseded by the availability of small bowel histology. Their use is not encouraged (C).

\subsection{INVESTIGATION OF MALABSORPTION DUE TO PANCREATIC INSUFFICIENCY}

\subsection{Introduction}

Chronic pancreatitis is accompanied by progressive destruction of both islet cells and acinar tissue. Loss of endocrine 
function generally occurs late in the course of chronic pancreatitis, although an impaired glucose tolerance test and even frank diabetes mellitus may be found in early or mild disease. ${ }^{113}{ }^{114}$ Loss of acinar tissue, responsible for the secretion of a wide array of enzymes essential for digestion of foodstuffs in the small intestine, leads to the characteristic malabsorption (or, more correctly, maldigestion) seen in pancreatic disease. This is difficult to distinguish clinically from malabsorption due to intestinal disease.

It is estimated that $90 \%$ of the pancreatic acinar tissue must be destroyed before symptoms of malabsorption become evident. ${ }^{115} 116$ Patients with steatorrhoea due to pancreatic insufficiency will therefore have very abnormal results on all tests of pancreatic function. A therapeutic trial of pancreatic enzyme supplementation may be employed as an alternative to estimating pancreatic function, although the diagnostic value of this approach has not been adequately studied. As pancreatic enzyme treatment is expensive and may not always control the diarrhoea of pancreatic insufficiency without dose adjustment and other therapeutic manipulations, this approach to diagnosis is not recommended.

\subsection{Invasive pancreatic function testing}

These tests measure exocrine function by analysing duodenal aspirate, either after direct stimulation of pancreatic secretion using secretin (with or without cholecystokinin) or after indirect stimulation by the use of a standard test meal as in the Lundh test. Direct tube tests have been regarded as the gold standard for assessing pancreatic function. ${ }^{117}{ }^{118}$ However, they require meticulous technique, are time consuming, expensive, uncomfortable for the patient, and are not standardised, although recent attempts to simplify the procedure have been made. ${ }^{119}$ To our knowledge they are no longer routinely performed in UK centres. Even the simpler Lundh test is seldom performed. This involves positioning of a single lumen tube in the duodenum. A test meal of glucose, corn oil, and casilan is given orally and four 30 minute aspirates are collected on ice to measure tryptic activity. The test is dependent on extrapancreatic factors such as gastric and vagal function, and endogenous secretin and cholecystokinin release. However, sensitivities of $90 \%$ for the detection of chronic pancreatitis across the whole range of the disease spectrum are achieved.

\subsection{Pancreatic imaging}

Part of the reason for the decline in the use of direct pancreatic function testing has been the growth and success of pancreatic imaging techniques: ultrasound, computerised tomography (CT), endoscopic retrograde cholangiopancreatography (ERCP), and latterly magnetic resonance cholangiopancreatography (MRCP). While hazardous, ERCP is, at present, the "gold standard" for the diagnosis of chronic pancreatitis and uses the presence of abnormal duct morphology for the detection of chronic pancreatic disease. ${ }^{120}$ Comparisons of ERCP with direct pancreatic function tests have shown considerable agreement: Rolny and colleagues ${ }^{121}$ compared ERCP with the secretin-cholecystokinin test and showed that in chronic pancreatitis, secretin stimulation was low in $26 / 30$ patients whereas ERCP showed an abnormal duct in 21 out of the same 30 patients. Two further studies have found a reasonably close relationship between ERCP and the secretin-pancreozymin test: approximately $10-15 \%$ of patients with normal pancreatograms will have abnormal secretin-pancreozymin results and $25 \%$ of patients with a normal secretin-pancreozymin test will have abnormal pancreatograms. ${ }^{118} 120122$

Although many units use ultrasound scanning for initial screening, this has a sensitivity of only $50-60 \%$ in chronic pancreatitis. ${ }^{123}{ }^{124}$ CT scanning has a sensitivity of $74-90 \%$ for pancreatic disease. ${ }^{125}$ Several studies have suggested that MRCP is as sensitive as ERCP for the detection of pancreatic disease (chronic pancreatitis and pancreatic carcinoma) $)^{126-128}$ and the recent development of MRI pancreatography after secretin stimulation may provide functional as well as structural information on the pancreas. ${ }^{129} 130$ Endoscopic ultrasound has also been reported to have a high sensitivity for the detection of early pancreatic disease $\mathrm{e}^{131-133}$ but its lack of wide availability limits the usefulness of this technique. Although the exact role of both endoscopic ultrasound and MRCP remain to be defined, it is likely that MRCP will become the imaging modality of choice for assessing pancreatic morphology.

\subsection{Non-invasive pancreatic function testing}

Because of the difficulty and, in the case of ERCP, the risk of performing invasive testing, there is a need for a simple, reliable, non-invasive test of pancreatic function. Many pancreatic function tests are available - an indication of the fact that none has yet achieved the goals of high levels of sensitivity and specificity while maintaining ease of use and interpretation.

\subsubsection{Serum enzymes}

The use of serum enzyme estimation in the diagnosis of pancreatic insufficiency is hampered by the fact that pancreatic disease must be very advanced before serum enzyme concentrations become significantly reduced. Three serum enzymes in particular have been used to assess pancreatic function: lipase, trypsin/trypsinogen, and amylase. Comparisons suggest that trypsin is the most useful of the three serum tests. ${ }^{134}{ }^{135}$ A combination of all three enzyme estimations has a higher positive predictive value but sensitivity appears to be poor. ${ }^{136}$ In a series of patients with pancreatic insufficiency, abnormally low serum enzymes were found in only $50 \%$ of cases. Although those patients with low serum enzymes invariably had a reduction to below $20 \%$ of the normal range, a substantial proportion of patients with marked functional impairment, as shown on invasive testing, had normal serum enzyme levels. ${ }^{137}$ Serum enzyme quantification is therefore not of value in the diagnosis of chronic pancreatitis.

\subsubsection{Faecal tests}

Pancreatic enzymes that have been measured in faeces include chymotrypsin, lipase, and elastase. There has been considerable controversy over the merits of stool measurement of chymotrypsin..$^{138-140}$ Many of the initial problems related to the assay have subsequently been refined and it has been used with some success in the diagnosis of pancreatic disease in cystic fibrosis and non-specific chronic pancreatitis. ${ }^{141}{ }^{142}$ Stool chymotrypsin has also been compared with the N-benzoyl-Ltyrosyl-p-aminobenzoic acid (NBTP-PABA) test and the secretin-caerulin test. ${ }^{143}$ The results revealed a good discriminatory capacity for those with normal and severely impaired pancreatic function, and the authors suggested that the faecal chymotrypsin test alone was sufficient in these groups but that patients with intermediate values require further confirmatory investigations.

Muench and colleagues ${ }^{144}$ investigated the use of stool lipase analysis. However, in their study of 231 patients, its sensitivity was only $46 \%$ in patients with clinical pancreatic insufficiency, and the further use of this enzyme assay in this context has not been pursued.

More recently, faecal elastase has been suggested as a suitable marker for pancreatic insufficiency ${ }^{145-147}$ This pancreas specific enzyme is not degraded during intestinal transport and reaches concentrations in faeces that are 5-6 times those found in duodenal juice. A commercially available ELISA using two monoclonal antibodies is highly specific for the enzyme. ${ }^{148}$ In a study of 79 patients, 44 of whom had abnormal secretin tests, Loser and colleagues ${ }^{146}$ found sensitivities of $63 \%, 100 \%$, and $100 \%$ for mild, moderate, and severe pancreatic insufficiency, respectively, although the number in the group with mild disease was small. There were also significant 
correlations with duodenal elastase, lipase, amylase, and trypsin. These results were similar to an earlier study by Amann and colleagues ${ }^{149}$ which concluded that the assay could not separate normal controls from those with "moderate" chronic pancreatitis. However, in the context of the diagnosis of pancreatic insufficiency as a cause of diarrhoea, faecal elastase appears to offer a reliable non-invasive test that is readily available. It also has been shown to discriminate well between diarrhoea of pancreatic and non-pancreatic origin. ${ }^{150}$

\subsubsection{Oral (tubeless) pancreatic function tests NBTP/PABA test}

This test is based on the luminal hydrolysis of (non-absorbed) N-benzoyl-L-tyrosyl-p- aminobenzoic acid (NBTP) by chymotrypsin, to release p-aminobenzoic acid (PABA), which is absorbed, conjugated in the liver, and excreted in urine where it can be measured. It requires an overnight fast, a test meal, and a 4-6 hour urine collection. The overall sensitivity for pancreatic disease varies between $64 \%$ and $83 \%,{ }^{151}{ }^{152}$ with specificities of $81-93 \%$ when non-diarrhoeal controls are used, but this falls to $50 \%$ when controls with non- pancreatic steatorrhoea or liver diseases are employed..$^{153}$ The test is not widely used: pharmaceutical grade reagents are not available in the UK.

\section{Fluorescein dilaurate test}

This is based on digestion of non-absorbed fluorescein dilaurate by pancreatic esterase to release lauric acid and fluorescein for absorption. The latter is then excreted in urine where it can easily be measured. The protocol involves an overnight fast followed by a standard test meal with fluorescein dilaurate on day 1 followed by a 6-10 hour urine collection. The procedure may be repeated on day 2 with fluorescein alone as a control, a 6-10 hour urine collection again being performed. The test is relatively inexpensive and is commercially available as the Pancreolauryl Test in the UK and shows good reproducibility. ${ }^{10}$ Sensitivity for detecting severe pancreatic insufficiency is at least $85 \% .{ }^{154-156}$

A meta-analysis of the available data ${ }^{157}$ has suggested that the Pancreolauryl and NBT- PABA tests have an equivalent sensitivity in mild/moderate disease $39 \%$ and $46 \%$, respectively) and in severe disease (79\% and $71 \%$, respectively) compared with invasive tube tests. Faecal chymotrypsin has a similar sensitivity (49\% for mild/moderate and $85 \%$ for severe pancreatic insufficiency). Lankisch et al has subsequently shown no difference in the sensitivity of faecal chymotrypsin compared with faecal elastase in mild, moderate, or severe pancreatic disease. ${ }^{158}$

\section{Summary and recommendations}

- Severe pancreatic insufficiency with malabsorption is normally associated with pancreatic duct abnormalities. At present ERCP offers the greatest sensitivity for the diagnosis of ductal changes. However, MRCP has the potential to replace ERCP as the imaging modality of choice and has the advantage of avoiding the risks associated with ERCP (B)

- Non-invasive pancreatic function tests include urine tests such as the Pancreolauryl test and stool tests such as faecal elastase or chymotrypsin. They depend on a significant loss of exocrine function and thus are only reliable in moderate/severe pancreatic disease, with poor sensitivity for mild disease (B)

- Non-invasive tests have approximately equivalent sensitivities for the detection of pancreatic insufficiency (B). Faecal elastase offers the advantages of acceptable reliability and convenience (a single stool sample is required) without the need for prolonged urine collections, and is therefore recommended as the test of first choice in patients who present with diarrhoea of putative pancreatic origin (C).

\subsection{INVESTIGATION OF CHRONIC DIARRHOEA DUE TO SPECIFIC CONDITIONS}

\subsection{Small bowel bacterial overgrowth}

7.1.1 Introduction

Despite food being non-sterile, and the high numbers of bacteria in the colon (concentrations of $10^{9}-10^{12}$ colony forming units $(\mathrm{cfu}) / \mathrm{ml})$, the small bowel normally has little bacterial colonisation. Gastric acidity, intestinal peristalsis (via the fasting motor migratory complex), and the ileocaecal valve help to produce steep oroduodenal and ileocolic bacterial gradients, with concentrations in the proximal jejunum of less than $10^{4}$ $\mathrm{cfu} / \mathrm{ml}$ in the normal healthy state.

Small bowel bacterial overgrowth (SBBO) is probably an underdiagnosed condition. Few data exist on its prevalence in patients presenting with diarrhoea and/or malabsorption. However, it is clear that specific groups of patients are particularly prone to SBBO. These include those with intestinal dysmotility syndromes associated with systemic disease (for example, diabetes, scleroderma, intestinal pseudoobstruction), and those with anatomical disorders of prior surgery (for example, terminal ileal resection) or strictures of the small bowel. Gastric surgery and, in particular, that involving a blind loop is associated with a high prevalence of SBBO: up to $50 \%$ of patients with gastrojejunostomy and vagotomy compared with $5 \%$ of those with vagotomy and pyloroplasty, although the clinical significance of this finding is unclear. ${ }^{160}{ }^{161}$ Other structural disorders of the small bowel such as jejunal diverticulosis are also associated with SBBO.

Considerable debate exists over the prevalence of SBBO in situations associated with achlorhydria such as old age or medical therapy with proton pump inhibitors. Lewis and colleagues ${ }^{162}$ found that $14.5 \%$ of asymptomatic residents in an elderly care home had a positive glucose hydrogen breath test suggesting SBBO, a value that should be regarded with some circumspection given the moderate sensitivity and specificity of this method for the detection of SBBO. Riordan and colleagues $^{163}$ found that $64 \%$ of individuals over 75 years with chronic diarrhoea had colonic-type flora cultured from small intestinal secretions. Other authors however have suggested that although achlorhydria in old age may result in a higher prevalence of culture positive SBBO, this is frequently of little clinical consequence. ${ }^{164-160}$

Part of the difficulty in establishing a confident diagnosis of SBBO is the lack of a standardised investigative tool. Culture of a small bowel aspirate is the most direct method of investigation of bacterial overgrowth and has been considered to be the gold standard for diagnosis of this condition by some authors. ${ }^{167}{ }^{168}$ The presence of greater than $10^{6}$ organisms $/ \mathrm{ml}$ in either aerobic or anaerobic conditions is conventionally regarded as the criteria for a positive culture. However, bacterial overgrowth, particularly due to coliforms and enterococci, may occur in apparently healthy individuals with no evidence of malabsorption ${ }^{164169}$ and so the clinical relevance of such a positive result may be difficult to determine. Although it appears that anaerobic organisms are primarily associated with malabsorptive syndromes, isolation and categorisation of bacterial anaerobes are not routinely performed in many laboratories. Furthermore, the lack of standardisation of bacterial counts, the possibility of sampling errors, and the need for intubation have led to a need for a less invasive simpler investigation.

\subsubsection{Breath tests}

Non-invasive breath tests have, for many years, been an attractive alternative to culture of small bowel aspirates. However, the sensitivity and specificity of these tests are, in general poor. One of the first tests to be developed was the bile acid ${ }^{14} \mathrm{C}$-glycocholate breath test ${ }^{170}$ based on the ability of anaerobic bacteria to deconjugate bile salts liberating glycine which, after absorption, is metabolised to labelled $\mathrm{CO}_{2}$ and can be 
measured in expired breath. This test is unable to differentiate bacterial overgrowth from ileal damage or resection. Because of its poor sensitivity, with a $30-40 \%$ false negative rate and poor specificity, this test has been largely abandoned.

Hydrogen breath testing is based on the ability of some bacteria to ferment carbohydrates with an end product of hydrogen, which is not produced by mammalian cells. It was originally proposed that breath testing after a carbohydrate load resulted in a double peak due to metabolism by small bowel bacteria, followed by a more prolonged peak due to metabolism by colonic bacteria. ${ }^{171}$ However, the reproducibility of this double peak pattern has been challenged. ${ }^{172}{ }^{173}$ The appearance of the initial peak is more likely to be due to fermentation by oropharyngeal flora. ${ }^{174}$ In addition, a false negative result may occur in those individuals whose bacterial flora are not hydrogen producers. Approximately 3-25\% of patients (depending on the population studied) do not have $\mathrm{H}_{2}$ producing bacteria. ${ }^{175}{ }^{176}$ This may in part be due to variations in the particular species of bacteria involved in small bowel colonisation as, for example, none of Staphlococcus aureus, Streptococcus viridans, Enterococci species, Serratia, or Pseudomonas species produce hydrogen.

Because of these problems, it is unsurprising that several studies have now shown the sensitivity and specificity of hydrogen breath tests to be low. Corazza and colleagues ${ }^{168}$ compared jejunal culture with glucose and lactulose-hydrogen breath tests and found sensitivities of $62 \%$ and $68 \%$, respectively, with a specificity of $83 \%$ for the glucose test and only $44 \%$ for lactulose. The particularly poor results with the $10 \mathrm{~g}$ lactulose test were confirmed by Riordan and colleagues, ${ }^{177}$ again using jejunal aspirate as the gold standard. Sensitivity was only $17 \%$ and specificity $70 \%$. The authors used scintigraphy to aid interpretation of the breath test, and this increased sensitivity to $39 \%$ and specificity to $100 \%$. The difficulties in interpreting the "double peak" were highlighted, and this was felt largely to be due to variations in orocaecal transit times and fermentation of carbohydrate in the caecum.

The explanation for the particularly poor sensitivity of the lactulose breath test is unclear. It has been shown that delays may occur in the increase in breath hydrogen concentration leading to a rise only after the test meal has already reached the caecum, ${ }^{178}$ especially if the orocaecal transit time is rapid. This problem underlies the use of all hydrogen breath tests and has been demonstrated in the glucose hydrogen breath test, namely that the wide variations in orocaecal transit may confuse interpretation. ${ }^{179}$ This is particularly relevant with regard to breath testing for SBBO in patients who have had a small bowel resection, a scenario in which the test is commonly used. In this situation the decreased transit time to the caecum makes interpretation extremely difficult.

The ${ }^{14} \mathrm{C}$-D-xylose $1 \mathrm{~g}$ breath test (or the ${ }^{13} \mathrm{C}$ test in children) has attracted considerable interest as an alternative to glucose or lactulose based methods, although it is not widely available. This initially showed promise ${ }^{180}{ }^{181}$ but subsequent studies have not confirmed this optimism..$^{182-184}$ The most recent comparison of ${ }^{14} \mathrm{C}$-D-xylose with a conventional glucose hydrogen breath test showed equivalent sensitivities of approximately $58 \%$ and $42 \%$ for glucose and ${ }^{14} \mathrm{C}$-D-xylose, respectively, in comparison with culture of small bowel aspirate. ${ }^{185}$ These findings suggest that the ${ }^{14} \mathrm{C}$-D-xylose breath test offers little advantage over the conventional glucose hydrogen breath test unless corrections for gastrointestinal motility and colonic transit are made. ${ }^{186}{ }^{187}$

Ultimately, there are theoretical and practical problems underlying the use of breath tests that limit their potential for substantial improvement. They are however relatively simple to perform and of value when positive. As a result they are likely to have a continued role in the investigation of SBBO. There is nonetheless a strong argument for strengthening facilities for microbiological analysis of gut flora after endoscopic sampling. Culture of unwashed mucosal biopsies may facilitate collection of microbiological samples rather than by using jejunal aspirates. ${ }^{188} 189$ An alternative and long established approach to diagnosis includes an empirical trial of antibiotics. ${ }^{190}$

\subsection{Bile salt malabsorption}

Bile acids are required for the absorption of dietary fats and sterols from the intestine. More than $90 \%$ are reabsorbed in the distal ileum by active uptake mechanisms. Malabsorption of bile acids, which can be due to either a primary defect, terminal ileal disease, or resection, leads to diarrhoea. Bile acid malabsorption (BAM) can be can be assessed by measurement of the turnover of radiolabelled bile acids, measurement of serum metabolites, or quantification of excreted bile acids. The first of these typically involves quantifying the faecal recovery of ${ }^{14} \mathrm{C}$ glycocholate in stool over $48-72$ hours after ingestion of an oral load of this marker. ${ }^{191}$ Measurement of serum concentrations of bile acid metabolites-for example, $7 \alpha$-hydroxy-4cholesten-3-one-avoids the use of radiolabels and has been shown to correlate results obtained by the ${ }^{75}$ Se homotaurocholate $\left({ }^{75} \mathrm{Se}-\mathrm{HCAT}\right){ }^{192}{ }^{193}$ but is seldom performed as the standard material is not commercially available. The ${ }^{75} \mathrm{Se}-\mathrm{HCAT}$ ) test is most widely used and involves ingestion of this synthetic analogue of the natural conjugated bile acid taurocholic acid. The retained fraction is assessed by a gamma camera seven days after oral administration. Values less than $15 \%$ suggest BAM. This can also be used to assess the functional integrity of the terminal ileum in cases where localised disease is suspected.

Patients with Crohn's disease or other terminal ileal abnormality or resection are particularly at risk of $\mathrm{BAM}^{194}$ but the condition has also been well documented following cholecystectomy, ${ }^{195}$ post-infectious diarrhoea, ${ }^{196}$ and in idiopathic diarrhoea. ${ }^{197-199}$ Nylin and colleagues ${ }^{194}$ found $90 \%$ of Crohn's patients with terminal ileal resections to have markedly abnormal SeHCAT retention ( $<5 \%$ at seven days). In a study of 181 patients who had chronic diarrhoea unexplained after full investigation, Williams and colleagues $^{197}$ found 60 patients to have some mild to severe abnormalities on SeHCAT scanning. Twenty one had seven day SeHCAT retention between $10 \%$ and $15 \%$, had symptoms compatible with IBS, and had no response to cholestyramine. Sixteen patients had results between $5 \%$ and $10 \%$, of whom six responded to bile acid chelators, while in the 23 who had SeHCAT retention $<5 \%$, all responded to cholestyramine. Further evidence as to the potential importance of BAM in idiopathic chronic diarrhoea or diarrhoea predominant IBS has recently been provided by Smith and colleagues ${ }^{199}$ who found that one third of such patients had evidence of BAM, the majority of whom responded to bile acid chelating agents.

In the absence of these diagnostic tests, a therapeutic trial of cholestyramine is sometimes employed, although the value of this approach has not been the subject of study.

There is evidence that equivalent information can be obtained from estimation in serum of 7-alpha cholestenone, but the test does not appear to be sufficiently widely available for this to be a general recommendation.

\subsection{Lactose malabsorption}

Lactase, the enzyme responsible for hydrolysis of dietary lactose, is located in the microvilli of small intestinal enterocytes. Lactase deficiency may lead to lactose malabsorption and hence a mild osmotic diarrhoea. Lactase activity decreases rapidly in most non-Caucasian population groups after the age of two years, and a relative lactase deficiency should be regarded as normal in these individuals. The exception is the northern European population where lactase activity may persist as a highly penetrant autosomal dominant characteristic. Lactase deficiency may also occur as a rare primary congenital defect or secondarily as a result of small bowel disease such as coeliac disease, gastroenteritis, or nonsteroidal anti-inflammatory drug use. 
Many methods exist for the detection of lactase deficiency but none represents a true "gold standard' for the diagnosis of this condition. These include (i) assay of mucosal lactase, (ii) breath tests (hydrogen, ${ }^{14} \mathrm{C}$-lactose and ${ }^{13} \mathrm{C}$-lactose), and (iii) lactose tolerance tests measuring either serum glucose or galactose in response to an oral lactose load. The lactose hydrogen breath test is the most widely used of these methods and is probably superior to lactose tolerance tests while of similar sensitivity and specificity to the mucosal lactase assay. ${ }^{200}$ It is also relatively easy to perform (particularly if an electrochemical cell is used for analysis) and is not invasive. The procedure involves ingestion of 25-50 g lactose dissolved in 200-500 ml water after an overnight fast. End expiratory breath samples are taken at 15-30 minute intervals for three hours. A rise of hydrogen concentration from basal levels by more than 20 parts per million is compatible with a positive diagnosis. However, due to a false negative rate of up to $25 \%$, a negative result does not exclude the diagnosis and hence a trial of a lactose free diet should be considered if the diagnosis is still suspected.

\subsection{Increased intestinal transit}

Many conditions associated with diarrhoea have been ascribed to abnormalities of gut motility and increased intestinal transit. These include post surgical states (for example, vagotomy, gastrectomy), endocrine conditions (for example, carcinoid, hyperthyroidism, diabetes), infiltrative small bowel disease, and, possibly, functional conditions such as IBS. However, our ability to assess the contribution of disordered motility to diarrhoeal syndromes is hampered by the facts that: (a) many of these conditions have multifactorial aetiologies, (b) diarrhoea itself can increase intestinal transit thus limiting the ability of available tests to distinguish cause and effect, and (c) there are wide individual variations in intestinal transit in healthy individuals limiting the ability to establish normal values.

The various methods employed in the measurement of orocaecal transit time (OCTT) include barium studies, radionucleotide scintigraphy, and the lactulose hydrogen breath test. The scintigraphic method may use both solid (for example, egg and toast) and liquid substrates, which are labelled with either ${ }^{99 \mathrm{~m}}$ technetium or ${ }^{111}$ indium-diethylene triamine pentacetic acid, and the time taken for the radioactive substrate to reach the caecum is recorded. This has been found to correlate well with the lactulose hydrogen breath test, which is considerably simpler, although the presence of lactulose may itself accelerate intestinal transit leading to a reduction in OCTT when measured by this method. ${ }^{201} 202$

Diarrhoea in diabetic patients has often been ascribed to abnormalities of small bowel motility due to autonomic neuropathy, although other factors such as steatorrhoea, bile acid malabsorption, and SBBO may be involved. Its prevalence is estimated at $2-10 \%,{ }^{203}$ predominantly occurring in type 1 diabetics with other manifestations of autonomic neuropathy. Diarrhoea may be continuous or intermittent, the latter often being difficult to distinguish from "functional" symptoms; diagnosis is difficult, other than by implication when autonomic neuropathy has been demonstrated.

\subsection{Hormone secreting tumours}

Hormone secreting tumours arising from pancreatic tissue are rare causes of diarrhoea. The prevalence of functional pancreatic endocrine tumours is approximately 10 per million population, the incidence ranging from $1 / 10^{6}$ cases per year in the case of gastrinomas to fewer than $1 / 10^{7}$ cases per year for vasoactive intestinal peptide (VIP)omas and glucagonomas. ${ }^{204}{ }^{205}$ Even this incidence value is likely to be an overestimate. Diarrhoea occurs as part of a symptom complex varying according to the tumour type (for example, 100\% cases in VIPoma; approximately $65 \%$ in gastrinoma). $\mathrm{Al}$ though diarrhoea has been reported at a prevalence of $15 \%$ in glucagonoma, this again is probably an overestimate. A wide variety of other symptoms may accompany hypersecretion of these hormones, and detailed discussion is available elsewhere. ${ }^{206} 207$

Confirmation of the diagnosis in each case requires demonstration of an elevated serum hormone concentration. A VIP secreting tumour may be suspected in the context of large volumes of secretory diarrhoea ( $>1$ litre/day), dehydration, and hypokalaemia. Normal values for circulating VIP are less than $170 \mathrm{pg} / \mathrm{ml}$ while mean VIP serum concentrations in patients with functioning tumours range from 675 to 965 $\mathrm{pg} / \mathrm{ml}^{208} 209210$ As serum levels fluctuate, the assay should be performed during an episode of diarrhoea. Similarly, serum gastrin levels in patients with gastrinomas are considerably higher than the normal range of $150 \mathrm{pg} / \mathrm{ml}$, with average values of approximately $1000 \mathrm{pg} / \mathrm{ml}$. However, comparable values can be found in patients with pernicious anaemia, other types of atrophic gastritis, or potent acid suppressant therapy. ${ }^{211} 212$ Raised levels, although not to the same degree, also occur in other conditions such as diabetes mellitus, renal insufficiency, and rheumatoid arthritis. In borderline cases, documentation of an increased basal acid output in gastric juice is of value. This involves gastric intubation and aspiration of gastric juice over 60 minutes after an overnight fast. A basal acid output of $>15 \mathrm{mmol} / \mathrm{h}$ is indicative of a gastrinoma in the presence of a raised serum gastrin. The test is inappropriate in patients with atrophic gastritis, pernicious anaemia, or if proton pump inhibitors have been used over the previous 14 days. In equivocal tests the intravenous secretin test may be necessary to confirm the diagnosis.

Diarrhoea is often a prominent feature in carcinoid syndrome. This almost always occurs in the context of hepatic metastases, even if the primary site remains undefined. The clinical diagnosis of "malignant disease" is usually evident. A 24 hour urinary 5-hydroxyindoleacetic acid has a high sensitivity and specificity for the condition and correlates with tumour bulk and, frequently, with the severity of symptoms.

\section{Summary and recommendations}

- Culture of small bowel aspirates is the most sensitive test for SBBO but methods are poorly standardised and positive results may not reflect clinically significant SBBO (B) Hydrogen breath tests have poor sensitivity but acceptable specificity, and are of value when a positive result is obtained. The glucose hydrogen breath test is recommended (B).

- In the absence of an optimal test for the presence of bacterial overgrowth, an empirical trial of antibiotics is often used; the value of this approach has not been subject to critical study (C).

- Bile acid malabsorption (BAM) may occur when there is terminal ileal disease or resection. Measurement of serum $7 \alpha$ hydroxy-4-cholesten-3-one is an effective test for this but is seldom performed. ${ }^{75} \mathrm{Se}$ homotaurocholate ${ }^{75} \mathrm{Se}$ HCAT) testing is more widely available and is a sensitive measure of BAM (B). In the absence of these tests a therapeutic trial of cholestyramine is sometimes employed as a test for the presence of BAM, but the validity of this approach has not been subject to study (B).

- Diarrhoea due to hormone secreting tumours is extremely rare and testing for the presence of excess vasoactive intestinal peptide, gastrin, or glucagon in plasma is recommended only in the presence of high volume watery diarrhoea when other causes of diarrhoea have been excluded (C)

\subsection{SUMMARY AND CONCLUSIONS}

Establishing a clear definition of diarrhoea based on history alone can prove difficult, and this tends to lead to over investigation of functional bowel disorders such as IBS. However, in 
the majority of such patients typical symptoms and negative initial investigations yield a positive diagnosis. In those patients where there is doubt, inspection of the stool and measurement of stool weight may prove helpful in clarifying whether there is true "diarrhoea" or functional disease. Initial investigations should include full blood count, erythrocyte sedimentation rate, electrolytes, liver function tests, iron studies, vitamin B12, folate, and thyroid function. Screening tests such as serum antiendomysium antibodies for coeliac disease, the most common small bowel enteropathy in European populations, should be performed early in the course of investigations. The initial assessment should direct the clinician to determine whether further investigation is necessary and, if so, whether the focus should be on colonic, small bowel, or pancreatic disease. This analysis could reasonably be performed in the primary care setting.

Most chronic diarrhoea is due to colonic disease, and in the absence of clinical evidence for malabsorption, investigations should focus on the lower gastrointestinal tract in the first instance. Colonic investigations should be age stratified, in keeping with the risk of neoplasia. This risk is greater in those with one or more first degree relatives with colorectal cancer and in males. Full colonic imaging is recommended in those over 45 years of age, preferably with colonoscopy. In patients younger than this the diagnostic yield of flexible sigmoidoscopy and biopsy is not substantially different from colonoscopy, and sigmoidoscopy can therefore be the preferred investigation.

Patients with malabsorption represent a small proportion of presentations with chronic diarrhoea. Supporting history may direct investigations towards either the small bowel or pancreas. Serological testing for coeliac disease will determine most cases without invasive investigation, but individuals suspected to have small bowel malabsorption, despite negative coeliac serology, should have endoscopic distal duodenal biopsies taken to exclude other rarer forms of small bowel enteropathy. This strategy has largely supplanted many of the older tests of small bowel function

Non-invasive tests for pancreatic insufficiency currently depend on the presence of at least moderate impairment of exocrine function before they achieve adequate sensitivity. There are indirect functional tests such as the BTP/PABA and Pancreolauryl tests, and more direct tests of pancreatic enzymes (such as elastase or chymotrypsin) in the stool Although the sensitivities and specificities are similar, faecal elastase is preferred because of its ease of use. These tests are reasonably specific for pancreatic malabsorption and are preferred over tests for faecal fat, which do not adequately discriminate between small bowel and pancreatic malabsorption. The three day faecal fat is often unreliable in clinical practice and is no longer recommended.

The optimal investigation for small bowel bacterial overgrowth remains unclear. Culture of jejunal aspirates or unwashed small bowel biopsies remains the gold standard and should be encouraged whenever the diagnosis is seriously considered. The sensitivity of hydrogen breath tests is only approximately $60 \%$, with little difference between ${ }^{14} \mathrm{C}$-D-xylose and glucose. Their specificity is approximately $75 \%$, which is better than for lactulose hydrogen breath testing.

Given the apparent deficiencies in the current methods for establishing diagnoses of pancreatic insufficiency, bile acid malabsorption, and small bowel bacterial overgrowth, an empirical trial of therapy is often employed. The diagnostic value of this approach has not been subject to evaluation.

Despite extensive and exhaustive investigations, some cases will resist a definitive diagnosis. Although no study has formally assessed an investigative protocol for chronic diarrhoea such as that described, it is estimated that approximately two thirds of cases can be diagnosed using such an approach. The remaining patients will be those with watery, secretory, self limiting "idiopathic" diarrhoea (presumably infective), or undiagnosed factitious diarrhoea. ${ }^{1323213}$ Since in the majority of these cases the overall prognosis appears to be good, further investigation in this group is not warranted and symptomatic treatment should be instituted.

\section{Authors' affiliations}

P Thomas, Department of Gastroenterology, Musgrave Park Hospital, Taunton, UK

A Forbes, Department of Gastroenterology, St Mark's Hospital, Harrow, UK

J Green, Department of Gastroenterology, Llandough Hospital, Penarth, UK

P Howdle, Department of Gastroenterology, St James's University Hospital, Leeds, UK

R Long, Department of Gastroenterology, City Hospital, Nottingham, UK R Playford, J Walters, Department of Gastroenterology, Hammersmith Hospital, London, UK

M Sheridan, Department of Radiology, St James's Hospital, Leeds, UK R Stevens GP, East Oxford Health Centre, Oxford, UK

R Valori, Department of Gastroenterology, Gloucestershire Roya Hospital, Gloucester, UK

G M Addison, Department of Clinical Chemistry, Royal Manchester Children's Hospital, Manchester, UK

P Hill, Department of Clinical Chemistry, Hope Hospital, Manchester, UK G Brydon, Clinical Scientist, Western General Hospital, Edinburgh, UK

Correspondence to: Dr A Forbes, St Mark's Hospital, Harrow, Middlesex HAl 3UJ, UK; alastair.forbes@ic.ac.uk

\subsection{REFERENCES}

Wenzl HH, Fine KD, Schiller LR, et al. Determinants of decreased fecal consistency in patients with diarrhea. Gastroenterology 1995; 108:1729-38.

2 Schiller LR, Hogan RB, Morawski SG, et al. Studies of the prevalence and significance of radiolabeled bile acid malabsorption in a group of patients with idiopathic chronic diarrhea. Gastroenterology 1987; $92: 151-60$

3 Madoff RD, Williams JG, Caushaj PF. Fecal incontinence. N Engl J Med 1992;326:1002-7.

4 Fine KD, Schiller LR. AGA technical review on the evaluation and management of chronic diarrhea. Gastroenterology 1999;116:146486.

5 Talley NJ, O'Keefe EA, Zinsmeister AR, et al. Prevalence of gastrointestinal symptoms in the elderly: a population-based study. Gastroenterology 1992;102:895-901.

6 Talley NJ, Weaver AL, Zinsmeister AR, et al. Onset and disappearance of gastrointestinal symptoms and functional gastrointestinal disorders. Am J Epidemiol 1992;136:165-77

7 Manning AP, Thompson WG, Heaton KW, et al. Towards positive diagnosis of the irritable bowel. BM 1978;2:653-54.

8 Thompson WG, Longstreth GF, Drossman DA, et al. Functional bowel disorders and functional abdominal pain. Gut 1999;45(suppl 2):1143-7.

9 Jones J, Boorman J, Cann P, et al. British Society of Gastroenterology guidelines for the management of the irritable bowel syndrome. Gut 2000;47(suppl 2):ii 1-19.

10 Duncan A, Hill PG. A UK survey of laboratory-based gastrointestinal investigations. Ann Clin Biochem 1998:35:492-503.

11 Talley NJ, Phillips SF, Melton L, et al. Diagnostic value of the Manning criteria in irritable bowel syndrome. Gut 1990;31:77-81.

12 Bytzer P, Stokholm M, Andersen I, et al. Aetiology, medical history, and faecal weight in adult patients referred for diarrhoea. A prospective survey. Scand J Gastroenterol 1990;25:572-8.

13 Bertomeu A, Ros E, Barragán V, et al. Chronic diarrhea with normal stool and colonic examinations: organic or functional? I Clin Gastroenterol 1991:13:531-6.

14 Isgar B, Harman M, Kaye MD, et al. Symptoms of irritable bowel syndrome in ulcerative colitis in remission. Gut 1983;24:190-2.

15 Thompson WG. Gastrointestinal symptoms in the irritable bowel compared with peptic ulcer and inflammatory bowel disease. Gut 1984:25:1089-92.

16 Tolliver BA, Herrera JL, DiPalma JA. Evaluation of patients who meet clinical criteria for irritable bowel syndrome. Am J Gastroenterol 1994;89:176-8.

17 Arrambide KA, Santa A, Schiller LR, et al. Loss of absorptive capacity for sodium chloride as a cause of diarrhea following partial ileal and right colon resection. Dig Dis Sci 1989:34:193-201.

18 Ros E, Zambon D. Postcholecystectomy symptoms. A prospective study of gall stone patients before and two years after surgery. Gut 1987:28: 1500-4

19 Suhr O, Danielsson A, Nyhlin $\mathrm{H}$, et al. Bile acid malabsorption demonstrated by SeHCAT in chronic diarrhoea, with special reference to the impact of cholecystectomy. Scand J Gastroenterol 1988;23:1187_ 94.

20 Valdovinos MA, Camilleri M, Zimmerman BR. Chronic diarrhea in diabetes mellitus: mechanisms and an approach to diagnosis and treatment. Mayo Clin Proc 1993;68:691-702. 
21 Persson J. Alcohol and the small intestine. Scand J Gastroenterol 1991;26:3-15

22 Jain NK, Rosenberg DB, Ulahannan M, et al. Sorbitol intolerance in adults. Am J Gastroenterol 1985;80:678-81.

23 Read NW, Krejs GJ, Read MG, et al. Chronic diarrhea of unknown origin. Gastroenterology 1980;78:264-71

24 Ackerman Z, Eliakim R, Stalnikowicz R, et al. Role of small bowel biopsy in the endoscopic evaluation of adults with iron deficiency anemia. Am J Gastroenterol 1996:91:2099-102.

25 Goddard AF, Mclntyre AS, Scott BB. Guidelines for the management of iron deficiency anaemia. British Society of Gastroenterology. Gut 2000;46(suppl 3-4):IV1-5.

26 Corazza GR, Andreani ML, Biagi F, et al. The smaller size of the 'coeliac iceberg' in adults. Scand J Gastroenterol 1997;32:917-19.

27 Collin $\mathbf{P}$, Reunala $T$, Rasmussen $M$, et al. High incidence and prevalence of adult coeliac disease. Augmented diagnostic approach. Scand J Gastroenterol 1997;32:1129-33

28 Not T, Horvath K, Hill ID, et al. Celiac disease risk in the USA: high prevalence of antiendomysium antibodies in healthy blood donors. Scand J Gastroenterol 1998;33:494-8.

29 Ascher H, Kristiansson B. The highest incidence of celiac disease in Europe: the Swedish experience. J Pediatr Gastroenterol Nutr 1997;24:S3-6

30 Catassi C, Ratsch IM, Fabiani E, et al. High prevalence of undiagnosed coeliac disease in 5280 Italian students screened by antigliadin antibodies. Acta Paediatr 1995;84:672-6.

31 Jansson U, Johansson C. Down syndrome and celiac disease. J Pediatr Gastroenterol Nutr 1995;21:443-5.

32 Dieterich W, Ehnis T, Baver $M$, et al. Identification of tissue transglutaminase as the autoantigen of celiac disease. Nat Med 1997:3:797-801.

33 Sugai E, Selvaggio G, Vazquez $H$, et al. Tissue transglutaminase antibodies in celiac disease: assessment of a commercial kit. Am J antibodies in celiac disease: assessm
Gastroenterol 2000;95:2318-22.

34 Malberg K, Malfertheiner P, Bannert N, et al. IgA-tissue transglutaminase ( $\mathrm{TTG}$ )- antibodies are highly sensitive serum markers for celiac disease. Am J Gastroenterol 1999;94:3079-80.

35 Biagi $\mathbf{F}$, Ellis HJ, Yiannakou JY, et al. Tissue transglutaminase antibodies in celiac disease. Am J Gastroenterol 1999.94:2 187-92.

36 Sardy M, Odenthal U, Karpati S, et al. Recombinant human tissue transglutaminase ELISA for the diagnosis of gluten-sensitive enteropathy. Clin Chem 1999;45:2142-9.

37 Sardy M, Karpati S, Peterfy F, et al. Comparison of a tissue transglutaminase ELISA with the endomysium antibody test in the diagnosis of gluten-sensitive enteropathy. Z Gastroenterol 2000;38:357-64

38 Dahele A, Kingstone K, Bode J, et al. Anti-endomysial antibody negative celiac disease: does additional serological testing help? Dig Dis Sci 2001;46:214-21

39 Collin P, Maki M, Keyrilainen O, et al. Selective lgA deficiency and coeliac disease. Scand J Gastroenterol 1992;27:367-71.

40 Cataldo F, Marino V, Bottaro G, et al. Celiac disease and selective immunoglobulin A deficiency. J Pediatr 1997;131:306-8.

41 Cataldo F, Marino V, Ventura A, et al. Prevalence and clinical features of selective immunoglobulin A deficiency in coeliac disease: an Italian multicentre study. Italian Society of Paediatric Gastroenterology and Hepatology (SIGEP) and "Club del Tenue" Working Groups on Coeliac Disease. Gut 1998;42:362-5.

42 Cataldo F, Lio D, Marino V, et al. IgG(1) antiendomysium and lgG antitissue transglutaminase (anti-tTG) antibodies in coeliac patients with selective $\lg A$ deficiency. Working Groups on Celiac Disease of SIGEP selective lgA deficiency. Working Groups on

43 Binder HJ. The gastroenterologist's osmotic gap: fact or fiction? Gastroenterology 1992;103:702-4

44 Eherer AJ, Fordtran JS. Fecal osmotic gap and $\mathrm{pH}$ in experimental diarrhea of various causes. Gastroenterology 1992:103:545-51.

45 Isaac-Renton JL. Laboratory diagnosis of giardiasis. Clin Lab Med $1991 ; 11: 811-27$.

46 Rosenblatt JE, Sloan LM, et al. Evaluation of an enzyme-linked immunosorbent assay for the detection of Giardia lamblia in stool specimens. Diagn Microbiol Infect Dis 1993;16:337-41

47 Mank TG, Zaat JO, Deelder AM, et al. Sensitivity of microscopy versus enzyme immunoassay in the laboratory diagnosis of giardiasis. Eur J Clin Microbiol Infect Dis 1997:16:615-19.

48 Markell E, Voge M, John D. Medical Parasitology. In: Markell E, Voge $M$, John D, eds. Medical Parasitology, 7th edn. Philadelphia: WB Saunders, 1992

49 Sugi K, Saitoh O, Hirata l, et al. Fecal lactoferrin as a marker for disease activity in inflammatory bowel disease: comparison with other neutrophil-derived proteins. Am J Gastroenterol 1996;91:927-34.

50 Tibble JA, Sigthorsson G, Bridger S, et al. Surrogate markers of intestinal inflammation are predictive of relapse in patients with inflammatory bowel disease. Gastroenterology 2000:119:15-22.

51 Limburg P, Ahlquist D, Sandborn W, et al. Fecal calprotectin levels predict colorectal inflammation amoung patients with chronic diarrhoea referred for colonoscopy. Am J Gastroenterol 2000;95:2831-7.

52 Duncan A, Morris AJ, Cameron A, et al. Laxative induced diarrhoea-a neglected diagnosis. J R Soc Med 1992;85:203-5.

53 Neims DM, McNeill J, Giles TR, et al. Incidence of laxative abuse in community and bulimic populations: a descriptive review. Int J Eat Disord 1995:17:211-28

54 Weltzin TE, Bulik CM, McConaha CW, et al. Laxative withdrawal and anxiety in bulimia nervosa. Int J Eat Disord 1995;17:141-6.
55 Ladefoged K, Schaffalitzky dM, Jarnum S. Faecal osmolality and electrolyte concentrations in chronic diarrhoea: do they provide diagnostic clues? Scand J Gastroenterol 1987:22:813-20.

56 Topazian M, Binder HJ. Brief report: factitious diarrhea detected by measurement of stool osmolality. N Engl J Med 1994;330:1418-19.

57 Duncan A, Cameron A, Stewart M, et al. Diagnosis of the abuse of magnesium and stimulant laxatives. Ann Clin Biochem 1991;28:568-73.

58 Perkins SL, Livesey JF. A rapid high-performance thin-layer chromatographic urine screen for laxative abuse. Clin Biochem 1993;26:179-81.

59 de Wolff FA, Edelbroek PM, de Haas EJ, et al. Experience with a screening method for laxative abuse. Hum Toxicol 1983;2:385-9

60 Plumeri PA. The room search. J Clin Gastroenterol 1984;6:181-5.

61 Marshall JB, Singh R, Diaz-Arias AA. Chronic, unexplained diarrhea: are biopsies necessary if colonoscopy is normal? Am J Gastroenterol 1995:90:372-6.

62 Fine KD, Seidel RH, Do K. The prevalence, anatomic distribution, and diagnosis of colonic causes of chronic diarrhea. Gastrointest Endosc 2000;51:318-26.

63 Guillem JG, Forde KA, Treat MR, et al. Colonoscopic screening for neoplasms in asymptomatic first-degree relatives of colon cancer patients. A controlled, prospective study. Dis Colon Rectum 1992;35:523-9.

64 Lieberman DA, Weiss DG, Bond JH, et al. Use of colonoscopy to screen asymptomatic adults for colorectal cancer. Veterans Affairs Cooperative Study Group 380. N Engl J Med 2000;343: 162-8

65 Bazzoli F, Fossi S, Sottili S, et al. The risk of adenomatous polyps in asymptomatic first-degree relatives of persons with colon cancer. Gastroenterology 1995;109:783-8.

66 Hunt LM, Rooney PS, Hardcastle JD, et al. Endoscopic screening of relatives of patients with colorectal cancer. Gut 1998;42:71-5.

67 Neugut Al, Garbowski GC, Waye JD, et al. Diagnostic yield of colorectal neoplasia with colonoscopy for abdominal pain, change in bowel habits, and rectal bleeding. Am J Gastroenterol 1993;88: 1179-83

68 Patel Y, Pettigrew NM, Grahame GR, et al. The diagnostic yield of lower endoscopy plus biopsy in nonbloody diarrhea. Gastrointest Endosc 1997:46:338-43

69 Lee JH, Rhee PL, Kim JJ, et al. The role of mucosal biopsy in the diagnosis of chronic diarrhea: value of multiple biopsies when colonoscopic finding is normal or nonspecific. Korean J Intern Med 1997;12:182-7.

70 Shah RJ, Fenoglio P, Bleau BL, et al. Usefulness of colonoscopy with biopsy in the evaluation of patients with chronic diarrhea. Am J Gastroenterol 2001;96:1091-5.

71 Zwas FR, Bonheim NA, Berken CA, et al. Diagnostic yield of routine ileoscopy. Am J Gastroenterol 1995;90:1441-3.

72 Geboes K, Ectors N, D'Haens G, et al. Is ileoscopy with biopsy worthwhile in patients presenting with symptoms of inflammatory bowe disease? Am J Gastroenterol 1998:93:201-6.

73 Mullhaupt B, Guller U, Anabitarte $M$, et al. Lymphocytic colitis: clinical presentation and long term course. Gut 1998;43:629-33.

74 Baert F, Wouters K, Haens G, et al. Lymphocytic colitis: a distinct clinical entity? A clinicopathological confrontation of lymphocytic and collagenous colitis. Gut 1999;45:375-81.

75 Offner FA, Jao RV, Lewin KJ, et al. Collagenous colitis: a study of the distribution of morphological abnormalities and their histological detection. Hum Pathol 1999;30:451-7

76 FernandezBanares F, Salas A, Forne $M$, et al. Incidence of collagenous and lymphocytic colitis: a 5-year population-based study. Am J Gastroenterol 1999;94:418-23.

77 Rex DK, Rahmani EY, Haseman JH, et al. Relative sensitivity of colonoscopy and barium enema for detection of colorectal cancer in clinical practice. Gastroenterology 1997; 112:17-23.

78 Winawer SJ, Stewart ET, Zauber AG, et al. A comparison of colonoscopy and double- contrast barium enema for surveillance after polypectomy. National Polyp Study Work Group. N Engl J Med 2000;342: 1766-72.

79 Rosenbusch G, Jansen JB, Reeders JW. Contemporary radiological examination of the small bowel. Baillieres Clin Gastroenterol 1994:8:683-700

80 Barloon TJ, Lu CC, Honda H, et al. Does a normal small-bowe enteroclysis exclude small-bowel disease? A long-term follow-up of consecutive normal studies. Abdom Imaging 1994;19:113-15.

81 Bernstein CN, Boult IF, Greenberg HM, et al. A prospective randomized comparison between small bowel enteroclysis and small bowel follow-through in Crohn's disease. Gastroenterology 1997;1 13:390-8.

82 Nolan DJ, Traill ZC. The current role of the barium examination of the small intestine. Clin Radiol 1997;52:809-20.

83 Bouhnik Y, Bitoun A, Coffin B, et al. Two way push videoenteroscopy in investigation of small bowel disease. Gut 1998;43:280-4.

84 Landi B, Tkoub M, Gaudric M, et al. Diagnostic yield of push-type enteroscopy in relation to indication. Gut 1998:42:421-5.

85 Segal AW, Ensell J, Munro JM, et al. Indium- 111 tagged leucocytes in the diagnosis of inflammatory bowel disease. Lancet 1981;2:230-2.

86 Gibson P, Lichtenstein M, Salehi N, et al. Value of positive technetium-99m leucocyte scans in predicting intestinal inflammation. Gut 1991;32:1502-7

87 Kennan N, Hayward M. Tc HMPAO-labelled white cell scintigraphy in Crohn's disease of the small bowel. Clin Radiol 1992:45:331-4.

88 Fine KD, Fordtran JS. The effect of diarrhea on fecal fat excretion. Gastroenterology 1992;102:1936-9. 
89 Hill P. Faecal fat: time to give it up. Ann Clin Biochem 2001;38:164-7.

90 Bo-Linn GW, Fordtran JS. Fecal fat concentration in patients with steatorrhea. Gastroenterology 1984;87:319-22.

91 Roberts IM, Poturich C, Wald A. Utility of fecal fat concentrations as screening test in pancreatic insufficiency. Dig Dis Sci 1986;31:1021-4.

92 Lembcke B, Grimm K, Lankisch PG. Raised fecal fat concentration is not a valid indicator of pancreatic steatorrhea. Am J Gastroenterol 1987; 82:526-31.

93 Bai JC, Andrush A, Matelo G, et al. Fecal fat concentration in the differential diagnosis of steatorrhea. Am J Gastroenterol 1989;84:27-30.

94 Benini L, Caliari S, Bonfante F, et al. Fecal fat concentration in the screening of steatorrhea. Digestion 1992;53:94-100.

95 Ventrucci M, Cipolla A, Di Stefano M, et al. Determination of fecal fat concentration by near infrared spectrometry for the screening of pancreatic steatorrhea. Int J Pancreatol 1998:23:17-23.

96 Amann ST, Josephson SA, Toskes PP. Acid steatocrit: a simple, rapid gravimetric method to determine steatorrhea. Am J Gastroenterol 1997;92:2280-4.

97 Fine KD, Ogunji F. A new method of quantitative fecal fat microscopy and its correlation with chemically measured fecal fat output. Am J Clin Pathol 2000;113:528-34

98 Nakamura T, Takeuchi T. Pancreatic steatorrhea, malabsorption, and nutrition biochemistry: a comparison of Japanese, European, and American patients with chronic pancreatitis. Pancreas 1997; 14:323-33.

99 Turner JM, Lawrence S, Fellows IW, et al. [14C]-triolein absorption: a useful test in the diagnosis of malabsorption. Gut 1987;28:694-700.

100 Duncan A, Cameron A, Stewart M, et al. Limitations of the triolein breath test. Clin Chim Acta 1992:205:51-64.

101 Einarsson K, Biorkhem I, Eklof R, et al. 14C-triolein breath test as a rapid and convenient screening test for fat malabsorption. Scand J Gastroenterol 1983:18:9-12.

102 Benini L, Scuro LA, Menini E, et al. Is the 14C-triolein breath test useful in the assessment of malabsorption in clinical practice? Digestion 1984;29:91-7.

103 Lembcke B, Braden B, Caspary WF. Exocrine pancreatic insufficiency: accuracy and clinical value of the uniformly labelled 13C-Hiolein breath test. Gut 1996;39:668-74.

104 Amarri S, Harding M, Coward WA, et al. 13Carbon mixed triglyceride breath test and pancreatic enzyme supplementation in cystic fibrosis. Arch Dis Child 1997;76:349-51.

105 Vantrappen GR, Rutgeerts PJ, Ghoos YF, et al. Mixed triglyceride breath test: a noninvasive test of pancreatic lipase activity in the duodenum. Gastroenterology 1989;96:1126-34.

106 Ventrucci M, Cipolla A, Ubalducci GM, et al. 13C labelled cholesteryl octanoate breath test for assessing pancreatic exocrine insufficiency. Gut 1998;42:81-7

107 Strygler B, Nicar M, Santangelo WC, et al. Alpha 1-antitrypsin excretion in stool in normal subjects and in patients with gastrointestinal disorders. Gastroenterology 1990:99:1380-7.

108 Waldmann TA, Wochner RD, Strober W. The role of the gastrointestinal tract in plasma protein metabolism. Studies with $51 \mathrm{Cr}$-albumin. Am J Med 1969;46:275-85

109 Ohkohchi N, Himukai M, Igarashi Y, et al. Mechanism of D-xylose transport in human small intestine. J Pediatr Gastroenterol Nutr 1986;5:372-8

110 Craig RM, Atkinson AJ. D-xylose testing: a review. Gastroenterology 1988;95:223-31.

111 Craig RM, Ehrenpreis ED. D-xylose testing. J Clin Gastroenterol 1999;29: 143-50

112 Biarnason I, MacPherson A, Hollander D. Intestinal permeability: an overview. Gastroenterology 1995;108:1566-81.

113 Ammann RW, Akovbiantz A, Largiader F, et al. Course and outcome of chronic pancreatitis. Longitudinal study of a mixed medical-surgical series of 245 patients. Gastroenterology 1984;86:820-8

114 Lankisch PG, Lohr-Happe A, Otto J, et al. Natural course in chronic pancreatitis. Pain, exocrine and endocrine pancreatic insufficiency and prognosis of the disease. Digestion 1993;54:148-55.

115 DiMagno EP, Go VL, Summerskill WH. Relations between pancreatic enzyme ouputs and malabsorption in severe pancreatic insufficiency. $N$ Engl J Med 1973;288:813-15

116 Lankisch PG, Lembcke B, Wemken G, et al. Functional reserve capacity of the exocrine pancreas. Digestion 1986;35:175-81.

117 Go VL, DiMagno EP. Assessment of exocrine pancreatic function by duodenal intubation. Clin Gastroenterol 1984;13:701-15.

118 Lankisch PG. Function tests in the diagnosis of chronic pancreatitis. Critical evaluation. Int J Pancreatol 1993;14:9-20.

119 Waxman I, Steer ML, Freedman SD. Endoscopically assisted direct pancreatic function testing: a simplified technique. Gastrointest Endosc 1996:44:630

120 Axon AT, Classen M, Cotton PB, et al. Pancreatography in chronic pancreatitis: international definitions. Gut 1984:25:1107-12.

121 Rolny P, Lukes PJ, Gamklou R, et al. A comparative evaluation of endoscopic retrograde pancreatography and secretin-CCK test in the diagnosis of pancreatic disease. Scand J Gastroenterol 1978;13:777-81.

122 Valentini M, Cavallini G, Vantini I, et al. A comparative evaluation of endoscopic retrograde cholangiopancreatography and the secretin-cholecystokinin test in the diagnosis of chronic pancreatitis: a multicentre study in 124 patients. Endoscopy 1981;13:64-7.

123 Lawson TL, Berland LL, Foley WD, et al. Ultrasonic visualization of the pancreatic duct. Radiology 1982;144:865-71.
124 Foley WD, Stewart ET, Lawson TL, et al. Computed tomography, ultrasonography, and endoscopic retrograde cholangiopancreatography in the diagnosis of pancreatic disease: a comparative study. Gastrointest Radiol 1980:5:29-35.

125 Luetmer PH, Stephens DH, Ward EM. Chronic pancreatitis: reassessment with current CT. Radiology 1989;171:353-7.

126 Sica GT, Braver J, Cooney M, et al. Comparison of endoscopic retrograde cholangiopancreatography with MR cholangiopancreatography in patients with pancreatitis. Radiology 1999:210:605-10.

127 Adamek HE, Albert J, Breer $\mathrm{H}$, et al. Pancreatic cancer detection with magnetic resonance cholangiopancreatography and endoscopic retrograde cholangiopancreatography: a prospective controlled study Lancet 2000;356:190-3

128 Robinson PJ, Sheridan MB. Pancreatitis: computed tomography and magnetic resonance imaging. Eur Radiol 2000;10:401-8.

129 Cappeliez O, Delhaye M, Deviere J, et al. Chronic pancreatitis: evaluation of pancreatic exocrine function with MR pancreatography after secretin stimulation. Radiology 2000;215:358-64.

130 Manfredi R, Costamagna G, Brizi MG, et al. Severe chronic pancreatitis versus suspected pancreatic disease: dynamic MR cholangiopancreatography after secretin stimulation. Radiology 2000;214:849-55.

131 Sahai AV, Zimmerman M, Aabakken L, et al. Prospective assessment of the ability of endoscopic ultrasound to diagnose, exclude, or establish the severity of chronic pancreatitis found by endoscopic retrograde cholangiopancreatography. Gastrointest Endosc 1998;48:18-25.

132 Catalano MF, Lahoti S, Geenen JE, et al. Prospective evaluation of endoscopic ultrasonography, endoscopic retrograde pancreatography, and secretin test in the diagnosis of chronic pancreatitis. Gastrointest Endosc 1998;48: 11-17.

133 Wallace MB, Hawes RH. Endoscopic ultrasound in the evaluation and treatment of chronic pancreatitis. Pancreas 2001;23:26-35

134 Ventrucci M, Gullo L, Daniele C, et al. Comparative study of serum pancreatic isoamylase, lipase, and trypsin-like immunoreactivity in pancreatic disease. Digestion 1983;28:114-21.

135 Jacobson DG, Curington C, Connery K, et al. Trypsin-like immunoreactivity as a test for pancreatic insufficiency. N Engl J Med 1984;310:1307-9

136 Dominguez-Munoz JE, Pieramico $O$, Buchler $M$, et al. Ratios of different serum pancreatic enzymes in the diagnosis and staging of chronic pancreatitis. Digestion 1993:54:231-6.

137 Ventrucci M, Pezzilli R, Gullo L, Plate L, et al. Role of serum pancreatic enzyme assays in diagnosis of pancreatic disease. Dig Dis Sci 1989:34:39-45

138 Durr HK, Otte M, Forell MM, et al. Fecal chymotroypsin: a study on its diagnostic value by comparison with the secretin-cholecystokinin test. Digestion 1978;17:404-9.

139 Ammann RW, Akovbiantz A, Hacki W, et al. Diagnostic value of the fecal chymotrypsin test in pancreatic insufficiency, particularly chronic pancreatitis: correlation with the pancreozymin-secretin test, fecal fat excretion and final clinical diagnosis. Digestion 1981;21:281-9.

140 Lankisch PG, Schreiber A, Otto J. Pancreolauryl test. Evaluation of a tubeless pancreatic function test in comparison with other indirect and direct tests for exocrine pancreatic function. Dig Dis Sci 1983;28:490-3.

141 Brown GA, Sule D. Williams J, et al. Faecal chymotrypsin: a reliable index of exocrine pancreatic function. Arch Dis Child 1988;63:785-9.

142 Lesi C, Melzi D'E, Scotta MS, et al. A new faecal chymotrypsin method for evaluating the exocrine pancreatic function in patients with different pancreatic diseases. Int J Pancreatol 1988;3:203-8.

143 Cavallini G, Benini L, Brocco G, et al. The fecal chymotrypsin photometric assay in the evaluation of exocrine pancreatic capacity. Comparison with other direct and indirect pancreatic function tests. Pancreas 1989:4:300-4.

144 Muench R, Ammann R. Fecal immunoreactive lipase: a new tubeless pancreatic function test. Scand J Gastroenterol 1992;27:289-94.

145 Glasbrenner B, Schön A, Klatt S, et al. Clinical evaluation of the faecal elastase test in the diagnosis and staging of chronic pancreatitis. Eur $J$ Gastroenterol Hepatol 1996;8:1117-20

146 Loser C, Mollgaard A, Folsch UR. Faecal elastase 1: a novel, highly sensitive, and specific tubeless pancreatic function test. Gut 1996;39:580-6.

147 Stein J, Jung M, Sziegoleit A, et al. Immunoreactive elastase I: clinical evaluation of a new noninvasive test of pancreatic function. Clin Chem 1996;42:222-6.

148 Sziegoleit A, Knapler H, Peters B. ELISA for human pancreatic elastase 1. Clin Biochem 1989:22:79-83.

149 Amann ST, Bishop M, Curington C, et al. Fecal pancreatic elastase 1 is inaccurate in the diagnosis of chronic pancreatitis. Pancreas 1996;13:226-30

150 Masoero G, Zaffino C, Laudi C, et al. Fecal pancreatic elastase 1 in the work up of patients with chronic diarrhea. Int J Pancreatol 2000;28:175-9.

151 Lang C, Gyr K, Stalder GA, et al. Assessment of exocrine pancreatic function by oral administration of N-benzoyl-L-tyrosyl-p-aminobenzoic acid (Bentiromide): 5 years' clinical experience. Br J Surg 1981;68:771-5.

152 Tanner AR, Fisher D, Ward C, et al. An evaluation of the one-day NBT-PABA/14C-PABA in the assessment of pancreatic exocrine insufficiency. Digestion 1984;29:42-6.

153 Mitchell CJ, Humphrey CS, Bullen AW, et al. The diagnostic value of the oral pancreatic function test. Scand J Gastroenterol 1979;14:183-7. 
154 Dominguez-Munoz JE, Pieramico $O$, Buchler $M$, et al. Clinical utility of the serum pancreolauryl test in diagnosis and staging of chronic pancreatitis. Am J Gastroenterol 1993:88:1237-41.

155 Lankisch PG, Brauneis J, Otto J, et al. Pancreolauryl and NBT-PABA tests. Are serum tests more practicable alternatives to urine tests in the diagnosis of exocrine pancreatic insufficiency? Gastroenterology 1986;90:350-4.

156 Lock G, Kadow R, Messmann H, et al. Modified serum pancreolauryl test in chronic pancreatitis: evaluation in comparison to endoscopic retrograde pancreatography. Hepatogastroenterology 1997:44:1110-16.

157 Niederau C, Grendell JH. Diagnosis of chronic pancreatitis. Gastroenterology 1985;88:1973-95.

158 Lankisch PG, Schmidt I, Konig H, et al. Faecal elastase 1: not helpful in diagnosing chronic pancreatitis associated with mild to moderate exocrine pancreatic insufficiency. Gut 1998;42:551-4.

159 Browning GG, Buchan KA, Mackay C. Clinical and laboratory study of postvagotomy diarrhoea. Gut 1974;15:644-53.

160 Biorneklett A, Fausa O, Midtvedt T. Small-bowel bacterial overgrowth in the postgastrectomy syndrome. Scand J Gastroenterol 1983;18:277-87

161 Bragelmann R, Armbrecht U, Rosemeyer D, et al. Small bowel bacterial overgrowth in patients after total gastrectomy. Eur J Clin Invest 1997;27:409-16.

162 Lewis SJ, Potts LF, Malhotra R, et al. Small bowel bacterial overgrowth in subjects living in residential care homes. Age Ageing 1999;28:181-5.

163 Riordan SM, Mclver CJ, Wakefield D, et al. Small intestinal bacterial overgrowth in the symptomatic elderly. Am J Gastroenterol overgrowth in the

164 Saltzman JR, Kowdley KV, Pedrosa MC, et al. Bacterial overgrowth without clinical malabsorption in elderly hypochlorhydric subjects. Gastroenterology 1994;106:615-23.

165 Lewis SJ, Franco S, Young G, O'Keefe SJ. Altered bowel function and duodenal bacterial overgrowth in patients treated with omeprazole. Aliment Pharmacol Ther 1996:10:557-61.

166 Hutchinson S, Logan R. The effect of long-term omeprazole on the glucose-hydrogen breath test in elderly patients. Age Ageing 1997; 26:87-9.

167 Kirsch M. Bacterial overgrowth. Am J Gastroenterol 1990;85:231-7.

168 Corazza GR, Menozzi MG, Strocchi A, et al. The diagnosis of small bowel bacterial overgrowth. Reliability of jejunal culture and inadequacy of breath hydrogen testing. Gastroenterology 1990;98:302-9.

169 Simon GL, Gorbach SL. The human intestinal microflora. Dig Dis Sci 1986:31:147S

170 Hofmann AF, Fromm H. New breath test for bile acid deconjugation. $N$ Engl J Med 1971;285:686-7

171 Rhodes JM, Middleton P, Jewell DP. The lactulose hydrogen breath test as a diagnostic test for small-bowel bacterial overgrowth. Scand J Gastroenterol 1979:14:333-6.

172 King CE, Toskes PP. Breath tests in the diagnosis of small intestine bacterial overgrowth. Crit Rev Clin Lab Sci 1984;21:269-81.

173 Bjorneklett A. Small bowel bacterial overgrowth syndrome. Scand J Gastroenterol Suppl 1983;85:83-93.

174 Thompson DG, O'Brien JD, Hardie JM. Influence of the oropharyngeal microflora on the measurement of exhaled breath hydrogen. Gastroenterology 1986:91:853-60.

175 Bond JH, Levitt MD. Use of breath hydrogen $(\mathrm{H} 2)$ to quantitate small bowel transit time following partial gastrectomy. J Lab Clin Med 1977:90:30-6

176 Saltzberg DM, Levine GM, Lubar C. Impact of age, sex, race, and functional complaints on hydrogen $(\mathrm{H} 2)$ production. Dig Dis $\mathrm{Sci}_{i}$ 1988;33:308-13

177 Riordan SM, Mclver CJ, Walker BM, et al. The lactulose breath hydrogen test and small intestinal bacterial overgrowth. Am J Gastroenterol 1996:91:1795-803.

178 Caride VJ, Prokop EK, Troncale FJ, et al. Scintigraphic determination of small intestinal transit time: comparison with the hydrogen breath technique. Gastroenterology 1984;86:714-20.

179 Sellin JH, Hart R. Glucose malabsorption associated with rapid intestinal transit. Am J Gastroenterol 1992;87:584-9.

180 King CE, Toskes PP, Spivey JC, et al. Detection of small intestine bacterial overgrowth by means of a 14C-D-xylose breath test. Gastroenterology 1979;77:75-82.

181 King CE, Toskes PP. Comparison of the 1-gram [14C]xylose, 10-gram lactulose-H2, and 80 -gram glucose- $\mathrm{H} 2$ breath tests in patients with smal intestine bacterial overgrowth. Gastroenterology 1986;91:1447-51.

182 Donald IP, Kitchingmam G, Donald F, et al. The diagnosis of small bowel bacterial overgrowth in elderly patients. J Am Geriatr Soc 1992; 40:692-6.

183 Valdovinos MA, Camilleri M, Thomforde GM, et al. Reduced accuracy of 14C-D-xylose breath test for detecting bacterial overgrowth in gastrointestinal motility disorders. Scand J Gastroenterol 1993;28:963-8.

184 Riordan SM, Mclver CJ, Duncombe VM, et al. Factors influencing the 1 -g 14C-D-xylose breath test for bacterial overgrowth. Am J Gastroenterol 1995;90:1455-60.
185 Stotzer PO, Kilander AF. Comparison of the 1-gram (14)C-D-xylose breath test and the 50-gram hydrogen glucose breath test for diagnosis of small intestinal bacterial overgrowth. Digestion 2000;61:165-71.

186 Chang CS, Chen GH, Kao CH, et al. Increased accuracy of the carbon-14 D-xylose breath test in detecting small-intestinal bacterial overgrowth by correction with the gastric emptying rate. Eur J Nucl Med $1995 ; 22: 1118-22$

187 Lewis SJ, Young G, Mann M, et al. Improvement in specificity of [14C]d-xylose breath test for bacterial overgrowth. Dig Dis Sci 1997:42:1587-92.

188 Riordan SM, Mclver CJ, Duncombe VM, et al. Bacteriologic analysis of mucosal biopsy specimens for detecting small-intestinal bacterial overgrowth. Scand J Gastroenterol 1995;30:681-5.

189 Stotzer PO, Brandberg A, Kilander AF. Diagnosis of small intestinal bacterial overgrowth in clinical praxis: a comparison of the culture of small bowel aspirate, duodenal biopsies and gastric aspirate. small bowel aspirate, duodenal biopsies and
Hepatogastroenterology 1998;45:1018-22.

190 Attar A, Flourie B, Rambaud JC, et al. Antibiotic efficacy in small intestinal bacterial overgrowth-related chronic diarrhea: a crossover, randomized trial. Gastroenterology 1999;117:794-7.

191 Schiller LR, Bilhartz LE, Santa A, et al. Comparison of endogenous and radiolabeled bile acid excretion in patients with idiopathic chronic diarrhea. Gastroenterology 1990;98:1036-43.

192 Eusufzai S, Axelson M, Angelin B, et al. Serum 7 alpha-hydroxy-4-cholesten-3-one concentrations in the evaluation of bile acid malabsorption in patients with diarrhoea: correlation to SeHCAT test. Gut 1993;34:698-701.

193 Brydon WG, Nyhlin H, Eastwood MA et al. Serum 7 alpha-hydroxy-4-cholesten-3-one and selenohomocholyltaurine (SeHCAT) whole body retention in the assessment of bile acid induced diarrhoea. Eur J Gastroenterol Hepatol 1996;8:1 17-23.

194 Nyhlin H, Merrick MV, Eastwood MA. Bile acid malabsorption in Crohn's disease and indications for its assessment using SeHCAT. Gut 1994;35:90-3.

195 Sciarretta G, Furno A, Mazzoni M, et al. Post-cholecystectomy diarrhea: evidence of bile acid malabsorption assessed by SeHCAT test. Am J Gastroenterol 1992;87:1852-4.

196 Niaz SK, Sandrasegaran K, Renny FH, et al. Postinfective diarrhoea and bile acid malabsorption. J R Coll Physicians Lond 1997;31:53-6.

197 Williams AJ, Merrick MV, Eastwood MA. Idiopathic bile acid malabsorption-a review of clinical presentation, diagnosis, and response to treatment. Gut 1991;32:1004-6.

198 Luman W, Williams A, Merrick MV, et al. Idiopathic bile acid malabsorption: long- term outcome. Eur J Gastroenterol Hepato 1995;7:641-5.

199 Smith M, Cherian P, Raju G, et al. Bile acid malabsorption in persistent diarrhoea. J R Coll Physicans Lond 2000;34:448-51.

200 Brummer RJ, Karibe M, Stockbrugger RW. Lactose malabsorption. Optimalization of investigational methods. Scand J Gastroenterol Suppl 1993;200:65-9.

201 Sciarretta G, Furno A, Mazzoni M, et al. Lactulose hydrogen breath test in orocecal transit assessment. Critical evaluation by means of scintigraphic method. Dig Dis Sci 1994;39:1505-10.

202 Miller MA, Parkman HP, Urbain JL, et al. Comparison of scintigraphy and lactulose breath hydrogen test for assessment of orocecal transit: lactulose accelerates small bowel transit. Dig Dis Sci 1997;42:10-18.

203 Saslow SB, Camilleri M. Diabetic diarrhea. Semin Gastrointest Dis 1995:6:187-93.

204 Buchanan KD, Johnston CF, Hare MM et al. Neuroendocrine tumors. A European view. Am J Med 1986;81:14-22.

205 Eriksson B, Oberg K, Skogseid B. Neuroendocrine pancreatic tumors. Clinical findings in a prospective study of 84 patients. Acta Oncol 1989;28:373-7.

206 Guillausseau PJ, Guillausseau-Scholer C. Glucagonomas: clinical presentation, diagnosis and advances in management. In: Mignon $M$, Jensen RT, eds. Endocrine Tumours of the Pancreas: Recent Advances in Research and Management. Basel, Switzerland: S Karger, 1995.

207 Matuchansky C, Rambaud JC. VIPomas and endocrine cholera: Clinical presentation, diagnosis and advances in management. In: Mignon $M$, Jensen RT, eds. Endocrine Tumours of the Pancreas: Recent Advances in Research and Management. Basel, Switzerland: S. Karger, 1995.

208 Long RG, Bryant MG, Mitchell SJ, et al. Clinicopathological study of pancreatic and ganglioneuroblastoma tumours secreting vasoactive intestinal polypeptide (vipomas). BM (Clin Res Ed) 1981;282:1767-71.

209 Krejs GJ. VIPoma syndrome. Am J Med 1987;82:37-48.

210 Mekhiian HS, Dorisio TM. VIPoma syndrome. Semin Oncol 1987:14:282-91.

211 Ganguli PC, Cullen DR, Irvine WJ. Radioimmunoassay of plasma gastrin in pernicious anaemia, achlorhydria without pernicious anaemia, hypochlorhydria, and in controls. Lancet 1971;1:155-8.

212 Korman MG, Strickland RG, Hansky J. Serum gastrin in chronic gastritis. BM 1971;2:16-18

213 Afzalpurkar RG, Schiller LR, Little KH, et al. The self-limited nature of chronic idiopathic diarrhea. N Engl J Med 1992;327:1849-52. 